\title{
Antiwear performance of ionic liquid+graphene dispersions with anomalous viscosity-temperature behavior
}

\author{
R. Pamies, M.D. Avilés, J. Arias-Pardilla, T. Espinosa, F.J. Carrión, J. Sanes, \\ M.D. Bermúdez
}

Grupo de Ciencia de Materiales e Ingeniería Metalúrgica. Departamento de Ingeniería de Materiales y Fabricación. Universidad Politécnica de Cartagena. Campus de la Muralla del Mar. C/Doctor Fleming, s/n. 30202-Cartagena (Spain)

\begin{abstract}
New dispersions of few-layers graphene $(\mathrm{G})$ in 1-ethyl-3-methylimidazolium ([EMIM]) ionic liquids (ILs) with dicyanamide ([DCA]) or bis(trifluoromethylsulfonyl)imide ([TFSI]) anions have been obtained by mechanical mixing and sonication. IL $+0.5 \mathrm{wt} . \% \mathrm{G}$ dispersions show constant viscosity values from $357 \mathrm{~K}$ (for IL=[EMIM][DCA]) or from $385 \mathrm{~K}$ (for $\mathrm{IL}=[\mathrm{EMIM}][\mathrm{TFSI}]$ ) to $393 \mathrm{~K}$. $\mathrm{IL}+\mathrm{G}$ dispersions with $\mathrm{G}>0.5$ wt.\% show linear viscosity increases with increasing temperature, from $306 \mathrm{~K}$ (for [EMIM][DCA]+1wt.\%G) and from 330K to 393K (for [EMIM][TFSI]+0.75wt.\%G and [EMIM][TFSI]+1wt.\%G). Addition of graphene improves the poor wear reducing performance of $[\mathrm{EMIM}][\mathrm{DCA}]$, and prevents surface damage on steel when added to [EMIM][TFSI]. Graphene increases the load-carrying ability of ILs, forms a surface layer on the sliding path and retains wear debris, preventing the formation of large abrasive particles.
\end{abstract}

Keywords: Ionic liquids; graphene; viscosity; lubrication. 


\section{Introduction}

Room-temperature ionic liquids (ILs) are molten salts with melting points below room temperature, which are generally formed by a combination of organic cations and organic or inorganic weakly coordinating anions. These ordered fluids present properties such as negligible vapor pressure, large liquid range, high thermal stability and ionic conductivity, which have attracted a growing interest in many scientific and technical fields, including lubrication and surface engineering [1-8]. The origin of ionic liquids can be traced back to XIX century, although the first protic ionic liquid, ethylammonium nitrate, was reported by Walden in 1914 [9]. However, it was not until 1992 that Wilkes and Zawarotko reported the first room-temperature ionic liquids which were stable in air and in water, the alkylimidazolium derivatives with the tetrafluoroborate or hexafluorophosphate anions [10]. The first report on the low friction coefficients afforded by fluorine-containing imidazolium ILs on a variety of contacts dates from 2001 [11]. Three years later, in 2004, graphene was obtained [12]. Graphene, a flat monolayer of $\mathrm{sp}^{2}$ carbon atoms, is presently one of the most widely investigated materials due to its unique structure, properties and potential applications [13] The applications of graphene for tribological purposes have been a very active field of research in recent years $[14,15]$.

It has been reported that non-polar lubricant oils cannot properly disperse graphene and, therefore, the nanomaterial must be modified [16]. Ionic liquids are excellent graphene dispersant media through van der Waals interactions and hindrance of self-assembly of the graphene plates [17]. The dispersion of graphene in ILs has been shown to achieve enhanced tribological performance $[6,15,18-21]$. The rheological study of ionic liquids, 
nanofluids and dispersions is an important aspect for their practical applications, particularly as thermal fluids and lubricants or lubricant additives [22].

For more than a decade since the first report by Ye et al. most ionic liquids studied as lubricant or lubricant additives $[8,23]$ were composed of anions containing heteroatoms such as halogens, in particular fluorine [24] phosphorus of sulfur, which are reactive and potentially corrosive, contaminant or hazardous. In the present search for more environmentally friendly or even biocompatible formulations, a growing number of studies consider the use of, not only halogen-free, but fully organic ionic liquids [25-27]. Such is the case of alkylimidazolium dicyanamide ILs.

1-alkyl-3-methylimidazolium dicyanamide room-temperature ionic liquids were first reported by MacFarlane et al. [27], and have been used as dispersants for single-walled carbon nanotubes (SWCNTs) [28, 29] and as initiators of epoxy polymerization in nanocomposites [30].

Imidazolium ILs with the dicyanamide anion exhibit lower density and viscosity than ILs containing other anions [31]. In particular, [EMIM][DCA] is the ionic liquid with the lowest viscosity at $298 \mathrm{~K}$ [32], presents Newtonian behavior over the range of shear rates from 10 to $10^{3} \mathrm{~s}^{-1}$, and a viscosity decrease with temperature [33], as expected.

Low concentrations $(0.03 \%)$ of graphene or graphene oxide reduce the viscosity of 1 butyl-3-methylimidazolium dicyanamide ([BMIM][DCA]) in the temperature range between 0 and $20^{\circ} \mathrm{C}$. In all cases, viscosity decreased with increasing temperature [34].

The rheological behavior and tribological applications of graphene-based nanofluids are currently the subject of much interest [35] and have been recently reviewed [36]. Several 
recent studies have addressed the problem of graphene-IL interactions, in particular for [EMIM]-derived ILs [37, 38].

1-ethyl-3-methylimidazolium dicyanamide has been described as inhibitor of steel corrosion [39], where the dicyanamide anion controls surface film formation. This precedent could anticipate also a good lubricating performance for steel. Previous reports on the tribological performance of [DCA]-derived ILs are very scarce [40, 41].

A simple relationship between fluidity, defined as the inverse of viscosity, and temperature has been described [42]. Fluidity and ionic conductivity decrease as alkyl chain lengths increase. This has been attributed to the increase in the van der Waals interactions between alkyl chains [43].

The highly non-spherical [DCA] anion [44] would generate a lower intermolecular friction than spherical anions such as $\left[\mathrm{BF}_{4}\right]$. Thus, the combination of the short alkyl chain [EMIM] cation and the non-spherical DCA anion gives rise to low viscosity, high fluidity ionic liquid [45].

The rheological behavior and tribological performance of the halogen-free $[\mathrm{EMIM}][\mathrm{DCA}]$ and its grapheme dispersions has been compared with that of [EMIM][TFSI], with the fluorinated, sulfur-containing bis(trifluoromehylsulfonyl)imide anion, which has been the object of interest in lubrication studies [46].

\section{Experimental}

Ionic liquids 1-ethyl-3-methylimidazolium dicyanamide ([EMIM][DCA]) and 1-ethyl-3methylimidazolium bis(trifluoromethanesulfonyl)imide ([EMIM][TFSI]) (Fig. 1) (purity $>98 \%$ ) and graphene (1-10 layers; purity > 99\%) (Fig. 2) were commercially available from Iolitec (Ionic Liquids Technologies GmbH, Germany). 
a)

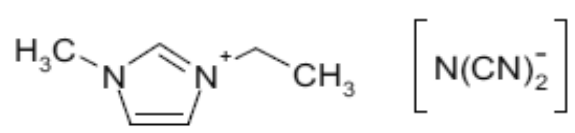

b)<smiles>CC[n+]1ccn(C)c1</smiles>

Fig. 1. Ionic liquids: a) 1-ethyl-3-methylimidazolium dicyanamide; b) 1-ethyl-3methylimidazolium bis(trifluoromethanesulfonyl)imide.

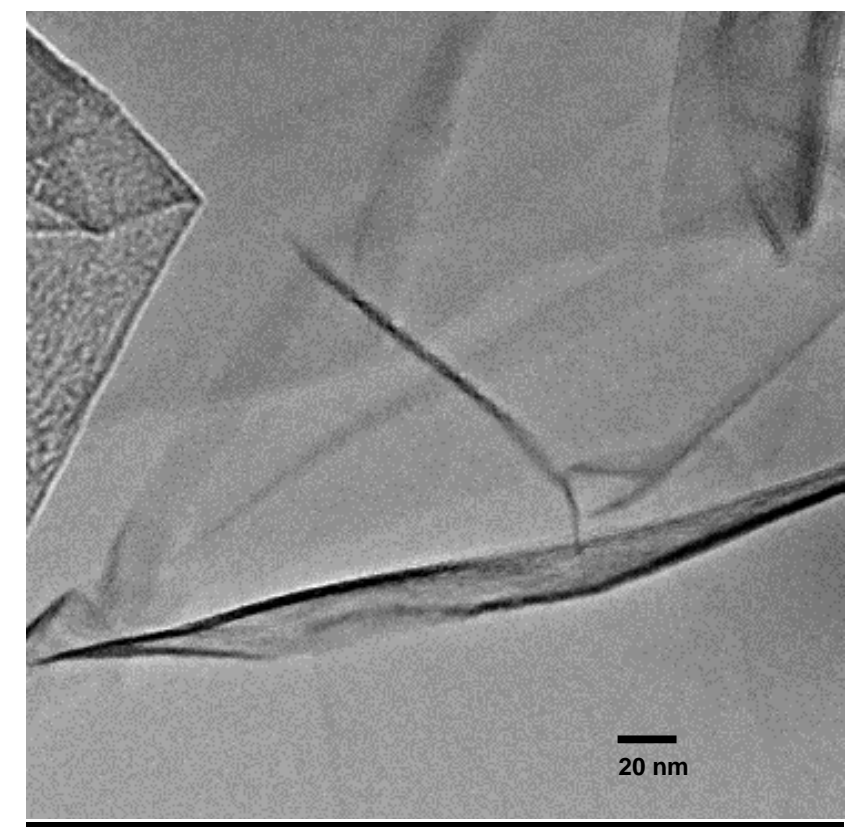

Fig. 2. TEM micrograph of as-received graphene.

The procedure for the preparation of the dispersions of graphene in ILs consisted in the addition of graphene to the ionic liquid in 0.5 or $1.0 \mathrm{wt} \%$ proportions following the method described in previous works $[20,21,47,48]$, by mechanical milling in an agate mortar for 10 minutes, followed by sonication for 30 minutes. 
The stability of the dispersions was monitorized before and after each rheological test in order to ensure the absence of phase segregation. The dispersions were stable at room temperature for a period of at least 2 months (Fig. S1, Supporting Information).

The rheological behavior of pure ionic liquids and the dispersion was determined using an AR-G2 rotational rheometer from TA instruments (New Castle, Delawere, USA). [28]. The instrument was calibrated (Fig. S2, Supporting Information) previously to the realization of rheological tests.

All experiments were carried out at least three times with a plate-plate configuration and the temperature was controlled by a Peltier system with an accuracy of $0.1^{\circ} \mathrm{C}$, using a plate-plate configuration with a diameter of the rotational plate of $60 \mathrm{~mm}$ and a gap between plates of $1000 \mu \mathrm{m}$.

The shear flow influence on the viscosity was studied at $25^{\circ} \mathrm{C}$ by increasing the shear rate from $10^{-3}$ to $500 \mathrm{~s}^{-1}$ in steady state.

The temperature dependence was evaluated with a reversible temperature ramp from 298 to $398^{\circ} \mathrm{C}$ at a constant shear rate of $50 \mathrm{~s}^{-1}$. The heating and cooling speed was set to 1 ${ }^{\circ} \mathrm{C} / \mathrm{min}$.

Tribological tests were carried out in a pin-on-disk tribometer (Anton Parr; Masó Analitica, Spain) under ambient conditions $\left(25 \pm 1^{\circ} \mathrm{C}\right.$; HR: $\left.50-60 \%\right)$. The materials used in tribological tests [49] were sapphire balls $\left(\mathrm{Al}_{2} \mathrm{O}_{3}\right.$ 99.9\%; hardness: $\left.2750 \mathrm{HV}\right)$ with 0.75 mm sphere radius and AISI 316L stainless steel (nominal composition in weight percentage: $<0.03 \mathrm{C}$; 16-18.5 Cr; 10-14 Ni; 2-3 Mo; $<2 \mathrm{Mn} ;<1 \mathrm{Si} ;<0.045 \mathrm{P} ;<0.03 \mathrm{~S}$; balance Fe); hardness: $195 \mathrm{HV}$ ) discs ( $25 \mathrm{~mm}$ diameter; $2.5 \mathrm{~mm}$ thickness). Before the tests, steel discs were polished to a final average surface roughness (Ra) of $0.12-0.13$ 
$\mu \mathrm{m}$, determined by means of a SM7 Profiltest contact profiler. A $0.5 \mathrm{~mL}$ lubricant volume was used, under a load of $0.98 \mathrm{~N}$ (mean contact pressure $1.30 \mathrm{GPa}$; maximum contact pressure $1.95 \mathrm{GPa}$ ), at a speed of $0.1 \mathrm{~m} / \mathrm{s}$ (sliding radius $9 \mathrm{~mm}$ ), and a total sliding distance of $1500 \mathrm{~m}$.

Wear tracks sections and volumes were determined with a Talysurf CLI 3D optical profiler.

Optical micrographs were obtained using a Leica DMRX optical microscope. SEM micrographs and EDX element maps were obtained with a Hitachi S-3500N.

Raman spectroscopy and transmission electron microscopy (TEM) techniques have been previously described [28].

\section{Results and discussion}

\subsection{Effect of shear rate.}

Fig. 3 shows the dependence of viscosity with increasing shear rate at room temperature for [EMIM][DCA] (Fig. 3a) and [EMIM][TFSI] (Fig. 3b) and their corresponding graphene dispersions, in 0.5 and $1 \mathrm{wt} . \%$ proportions.

As expected, [EMIM][DCA] shows much lower viscosity values than [EMIM][TFSI] and an increase in graphene content increases the viscosity values, but this increase is higher in the case of [EMIM][TFSI]. In particular, the addition of $0.5 \mathrm{wt} . \%$ graphene increases the final viscosity at $500 \mathrm{~s}^{-1}$ in a $48.5 \%$ with respect to [EMIM][DCA] and in a $70.5 \%$ with respect to [EMIM][TFSI], while the increase by the addition of $1 \mathrm{wt} . \%$ graphene is of $151 \%$ with respect to [EMIM][DCA] and a $269 \%$ for [EMIM][TFSI]. 
a)

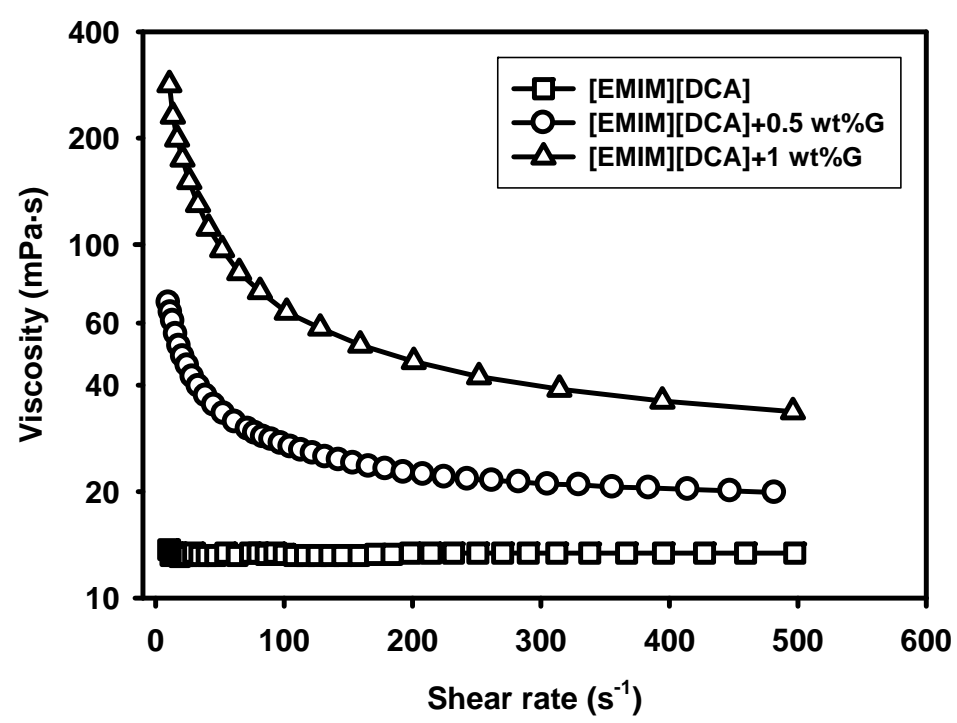

b)

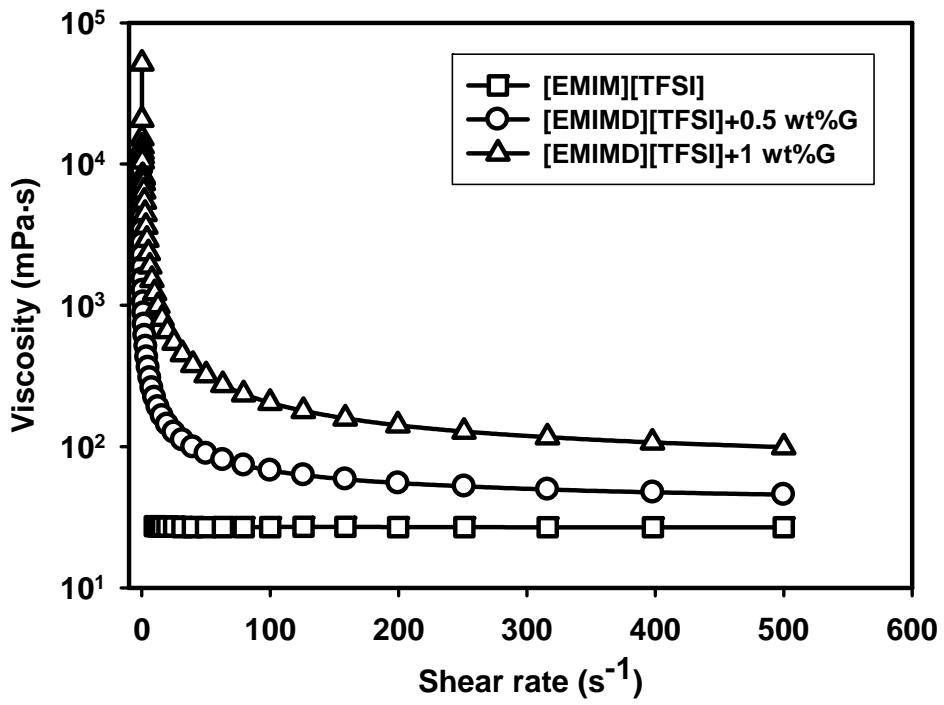

Fig. 3. Viscosity dependence on shear rate at $25^{\circ} \mathrm{C}$ : a) [EMIM] [DCA] and graphene dispersions; b) [EMIM][TFSI] and graphene dispersions. 
Both neat ILs show a Newtonian behavior, with constant viscosity values under the whole range of shear rates. In contrast, graphene-containing dispersions are NonNewtonian fluids, which show shear thinning behaviors, particularly pronounced under low shear. As shear rate increases, the viscosities of IL+graphene dispersions show a more similar behavior to that of the neat ILs. These results could be attributed to more homogeneous graphene dispersion, and the absence of large aggregates which oppose to flow.

3.2. Viscosity values as a function of temperature.

\subsubsection{Ionic liquids.}

Fig. 4 shows the decrease of viscosity with increasing temperature for neat [EMIM][DCA] (Fig. 4a) and [EMIM][TFSI] (Fig. 4b) in the range from 298 to 393K, and the good agreement with previously described results for [EMIM][DCA] $[32,33]$ and [EMIM][TFSI] [50-52]. E. Quijada-Maldonado et al. have shown [33] that the dynamic viscosity of pure ILs strongly decreases with temperature. The data described for [EMIM][DCA] are shown in Fig. 5a, and are in agreement with the experimental results found in the present work. Shi et al. [53], have established a relationship between the electrical conductivity and dynamic viscosity values of ionic liquids containing the 1ethyl-3-metylimidazolium ([EMIM]) cation. When the anion is dicyanamide, the ionic liquid ([EMIM][DCA]) shows the highest conductivity and the lowest viscosity values. This behavior has been explained by the low hydrogen bond accepting ability of the small size dicyanamide anion with respect to other anions containing fluorine, sulphur or oxygen atoms, such as [TFSI]. 
a)

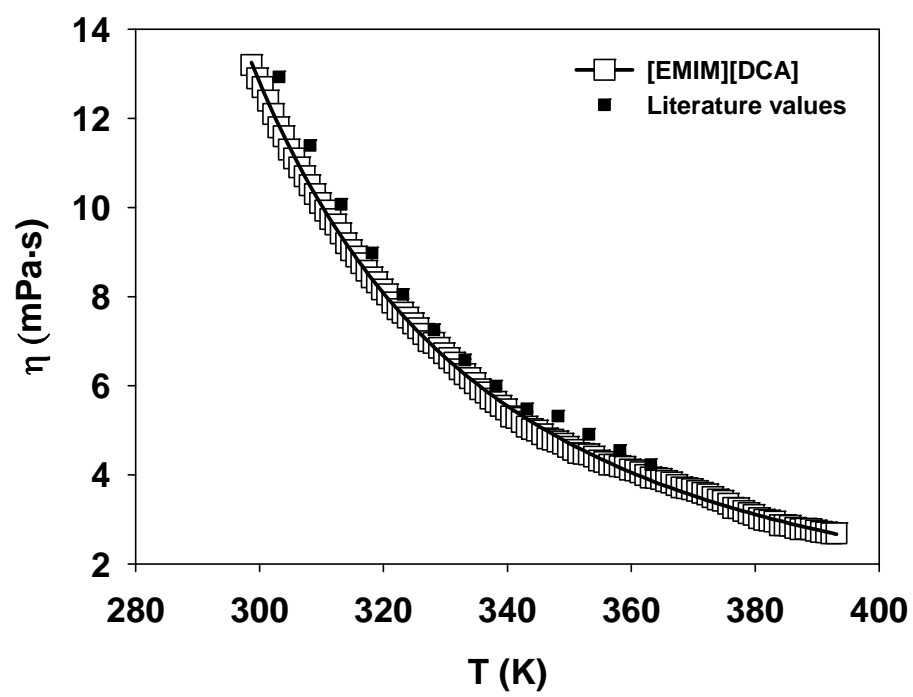

b)

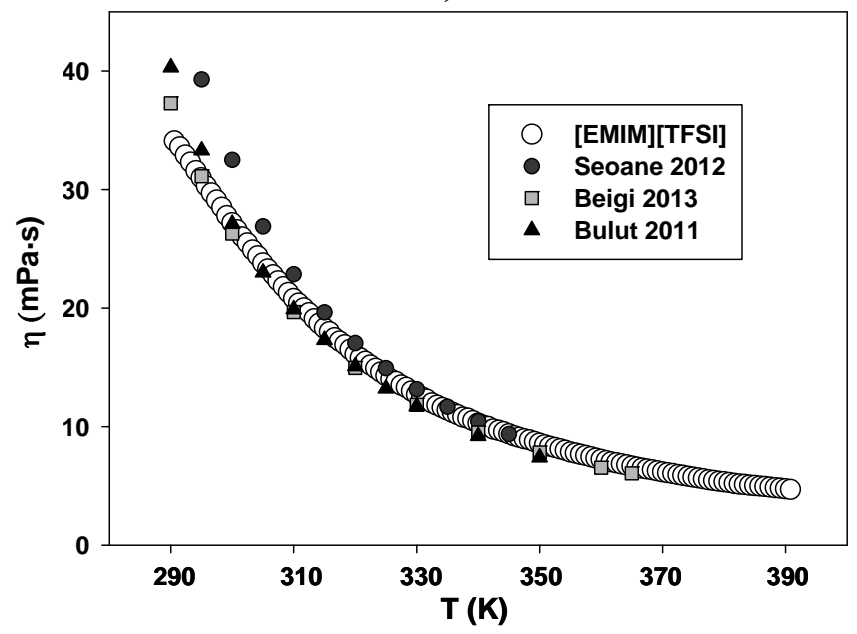

Fig. 4. Viscosity as a function of temperature and literature values for neat ILs: a) $[$ EMIM] [DCA]; b) [EMIM][TFSI].

$\mathrm{Ab}$ initio molecular dynamics calculations carried out for cyano-based ethylmethylimidazolium ionic liquids by Weber and Kirchner [54] are in agreement with strong hydrogen bonding for $[\mathrm{EMIM}][\mathrm{DCA}]$, with the dicyanamide anion on top of the imidazolium ring. However, experimental viscosity values correlate with cation-cation dynamics rather than with the slow hydrogen bond dynamics found for [DCA] 


\subsubsection{IL + graphene dispersions}

Previous results have shown a reduction in the viscosity of ILs with the addition of low concentrations $\left(0.005\right.$ or $0.01 \mathrm{wt} . \%$ of graphene to [BMIM] $\left[\mathrm{BF}_{4}\right]$ [54] or 0.03 and $0.06 \%$ graphene to [HMIM][BF 4 [55]).

Addition of a 0.5 wt.\% graphene to [EMIM][DCA] (Fig. 5a) increases viscosity, and shows the expected behavior, with a reduction of viscosity with increasing temperature, up to $357 \mathrm{~K}$. From that temperature to the end of the test, viscosity remains constant around a mean value of $18.9 \mathrm{mPa} \cdot \mathrm{s}$. This constant viscosity with temperature is in contrast with the behavior of the IL, but has been previously reported for ionanofluids [56].

As expected, when the graphene concentration in [EMIM][DCA] is increased to $1 \mathrm{wt} . \%$ (Fig. 5b) the viscosity is increased with respect to the neat IL and to the $0.5 \mathrm{wt} . \%$ graphene dispersion. However, the variation of viscosity with temperature shows an anomalous trend, as it only decreases with increasing temperature between 298 and $303 \mathrm{~K}$, to reach a minimum of $91.7 \mathrm{mPa} \cdot \mathrm{s}$. From $303 \mathrm{~K}$ to $393 \mathrm{~K}$, the viscosity values of $[\mathrm{EMIM}][\mathrm{DCA}]+1 \mathrm{wt} . \%$ graphene show a linear increase with increasing temperature, with a slope of $2 \times 10^{-4}$.

Addition of low concentrations of graphene to [EMIM][TFSI] (Fig. S3, Supporting Information) produces no significant changes in the rheological behavior with respect to neat IL. As graphene contents are increased (Fig. 6), the influence of temperature is similar to that found for [EMIM][DCA]+graphene. For [EMIM] [TFSI] $+0.5 \% \mathrm{G}$, viscosity becomes asymptotic with temperature and remains constant, with a value of $53 \mathrm{mPa} \cdot \mathrm{s}$, from 385 to $393 \mathrm{~K}$. As expected [57], viscosity values increase with increasing graphene 
concentration, in the whole temperature range. A graphene concentration higher than 0.5 wt.\%, not only hinders the movement of IL molecules, but produces a linear viscosity increase with increasing temperature values, from 330 to $393 \mathrm{~K}$. The slope increases with graphene content, from 0.59 for $[\mathrm{EMIM}][\mathrm{TFSI}]+0.75 \mathrm{wt} \% \mathrm{G}$ to 1.21 for [EMIM][TFSI]+1wt.\%G.

These results are attributed to strong interactions between graphene sheets and IL molecules.

The adsorption of imidazolium ILs has been studied by quantum theory [58]. The results indicate that the hydrogen bond strength between cation and anion in ILs decreases upon adsorption on the graphene surface, showing the $\pi-\pi, \mathrm{C}-\mathrm{H}-\pi$ interactions in the adsorption of ILs on graphene. Thermochemical analysis results indicate that the energy of adsorption of ILs on graphene is negative and adsorption occurs spontaneously. Adsorption of ILs on graphene also reduces entropy due to the decrease in the translation degree of freedom of IL molecules. Molecular dynamic results described by Pensado et al. [38] for [EMIM] thiocyanate IL on a flat graphene surface have shown that both anions and cations are present in the first one ion thick layer.

The presence of [EMIM][TFSI] on dry graphene from the [EMIM][TFSI]+graphene dispersions described here can be observed by EDX fluorine, oxygen and sulfur element maps (Fig. S4, Supporting Information). 
a)

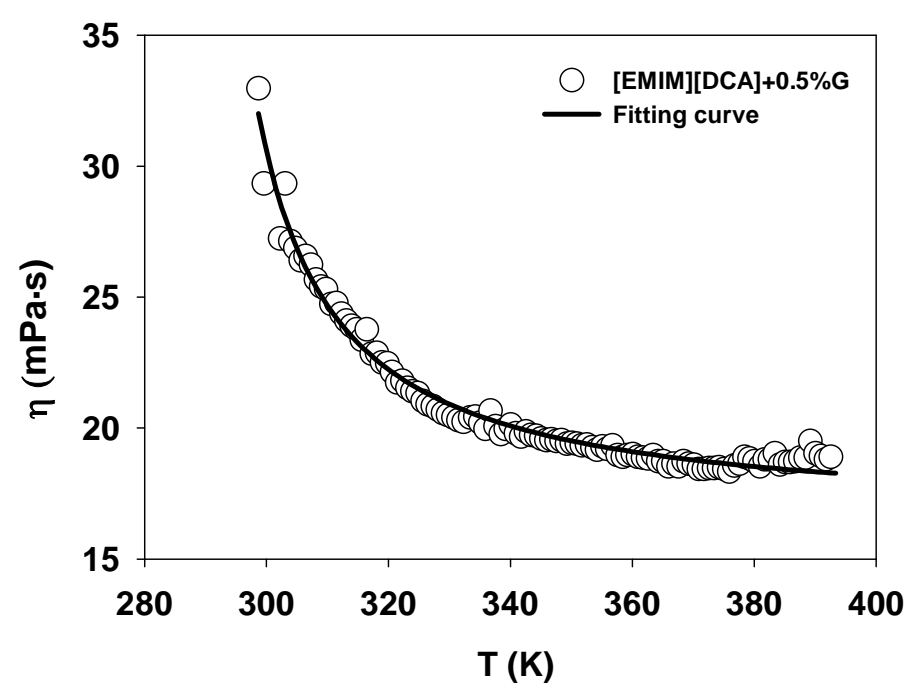

b)

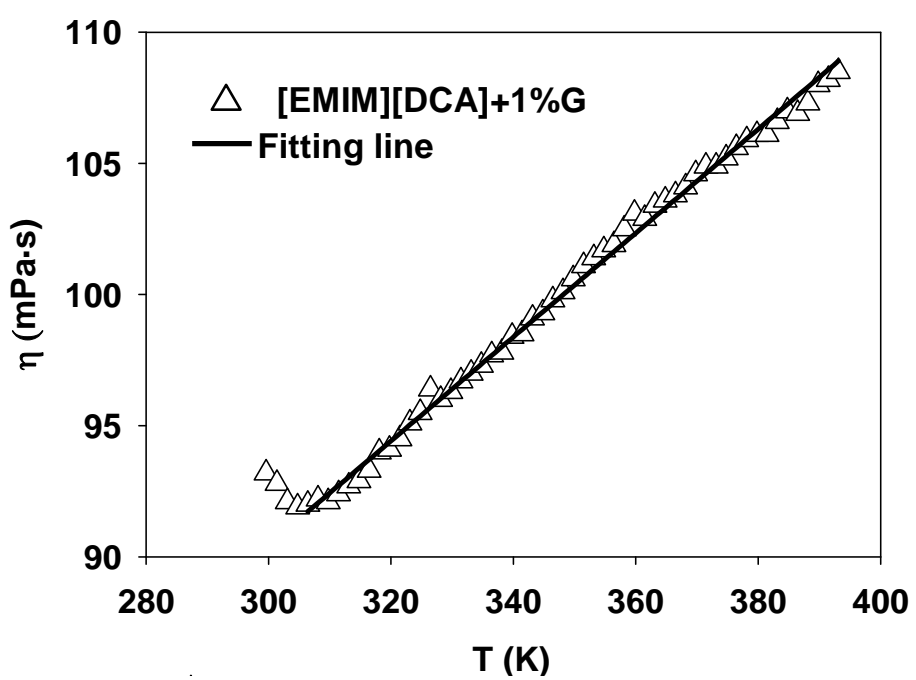

Fig. 5. Viscosity $(\eta)$ vs temperature for: a) $[$ EMIM] $[D C A]+0.5 \%$ graphene and b) $[\mathrm{EMIM}][\mathrm{DCA}]+1 \%$ graphene. 


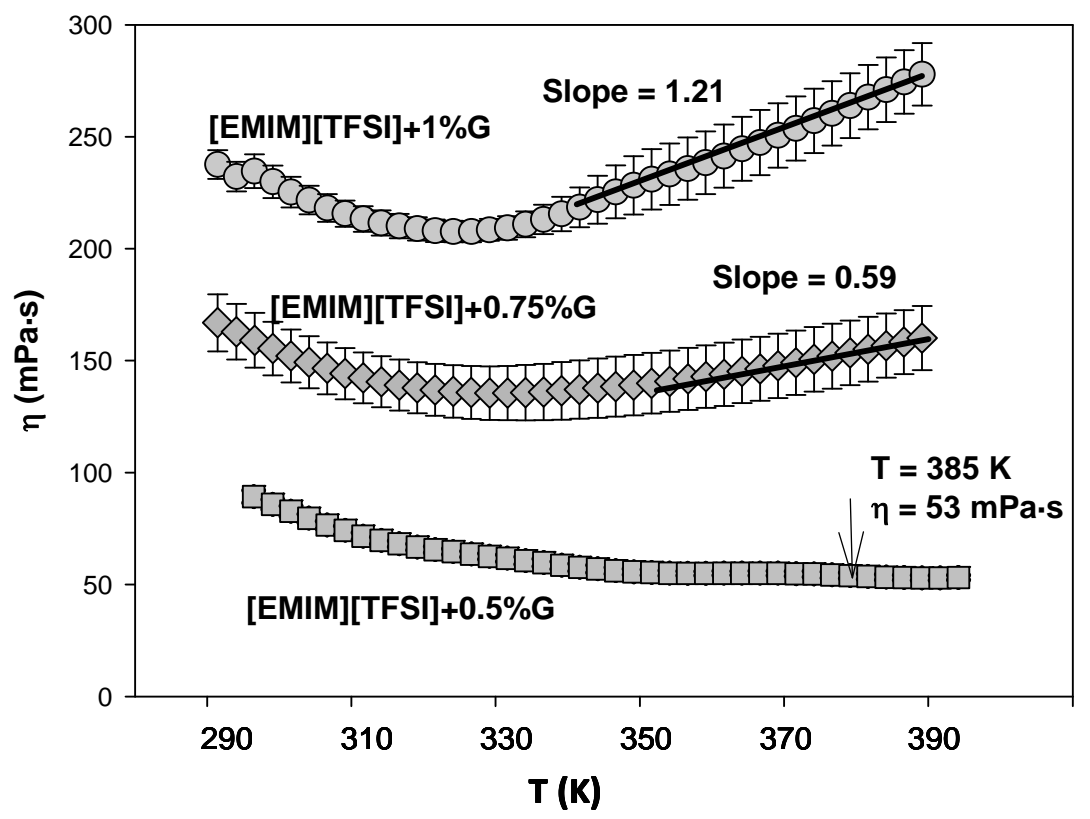

Fig. 6. Viscosity $(\eta)$ vs temperature for [EMIM][TFSI] +graphene dispersions.

The interactions between nanophases and base fluids and their influence on the rhelogical properties of nanofluids have been previously discussed [59]. An increase in concentration increases internal shear stress, with the subsequent viscosity increase. However, there are no direct precedents for the rheological behavior of the new ILgraphene dispersions described here.

The growth of micelles in cationic surfactant solutions [60] are among the scarce previously described observations of increasing viscosity with temperature. A. Chagnes et al. [61] found an increase of viscosity with temperature at low concentrations of IL in water. They attributed these results to the formation of hydrogen bonds between the IL molecules and methanol. Other unusual rheological behaviors, such as a linear dependency with temperature have been recently described for aqueous solutions of ionic 
liquids [62]. This result has been explained by the dynamic heterogeneities of the systems which changes the structural organization of IL molecules with formation of aggregates. Formation of large aggregates or segregation of the nanophase has not been observed in the present case, as the dispersions are stable over a large period of time. The ILgraphene interactions that would be responsible for the decrease in fluidity with increasing temperature are reversible, as low viscosity values are recovered upon cooling to room temperature (Fig.s S5 and S6, Supporting Information).

\subsection{Viscosity correlation}

Different models have been proposed for viscosity of liquids with ionic constituents, the most commonly applied are those of Arrhenius for non-associating electrolytes, Litovitz [63] for associated liquids and Vogel-Fulcher-Tammann-Hesse (VFTH) [64-66] for glass-forming liquids. This last model usually gives the best correlation for ionic liquids [67].

The VFTH model for the variation of viscosity $(\eta)$ with temperature $(T)$ follows Equation 1:

$$
\eta=\mathrm{A} \cdot \mathrm{e}^{\mathrm{k} /\left(\mathrm{T}-\mathrm{T}_{\mathrm{o}}\right)}
$$

Eq. 1

were $A$ is the viscosity at infinite temperature, $T_{o}$ is the "ideal" glass transition temperature at which the free volume of the liquid disappears, liquid transport becomes impossible [68] and the configurational entropy of the liquid vanishes, and $k$ is a constant, the ratio $\mathrm{k} / \mathrm{R}$ (where $\mathrm{R}$ is the universal gas constant) being related to the Arrhenius activation energy. 
Those fluids that present a good correlation with the Arrhenius law are called strong glass formers, while those that deviate from the Arrhenius-type behavior are classified as fragile glass formers. ILs show fragile or intermediate behaviors [69].

As can been observed in Table 1, viscosity values of neat ILs and diluted graphene dispersions (Fig. S3, Supporting Information) in [EMIM][TFSI] between 298-393 K show a good correlation with the VFTH model, as has previously been observed in different works using other ionic liquids $[51,70]$.

Table 1. Fitting parameters for the viscosity data of ionic liquids and ionic liquid+graphene dispersions according to VFTH model.

\begin{tabular}{|l|c|c|c|c|}
\hline \multicolumn{1}{|c|}{ Fluid } & $\begin{array}{c}\mathrm{A} \\
(\mathrm{mPa} \cdot \mathrm{s})\end{array}$ & $\begin{array}{c}\mathrm{k} \\
(\mathrm{K})\end{array}$ & $\begin{array}{c}\mathrm{T}_{\mathrm{o}} \\
(\mathrm{K})\end{array}$ & $\mathrm{R}^{2}$ \\
\hline [EMIM][DCA] & $13 \pm 1$ & $809 \pm 40$ & $122 \pm 5$ & 0.9993 \\
\hline [EMIM][TFSI] & $8 \pm 1$ & $1200 \pm 100$ & $90 \pm 9$ & 0.9976 \\
\hline [EMIM][TFSI]+0.05\%G & $120 \pm 10$ & $330 \pm 20$ & $198 \pm 3$ & 0.9939 \\
\hline [EMIM][TFSI]+0.1\%G & $100 \pm 7$ & $400 \pm 20$ & $186 \pm 4$ & 0.9951 \\
\hline
\end{tabular}

The rheological behavior of concentrated graphene dispersions in the ILs could not be fitted to any previously described theoretical model.

\subsection{Friction reducing and antiwear performance.}

The strong viscosity increase produced by graphene, could increase the friction coefficient of IL+graphene lubricants with respect to IL. On the other hand, this viscosity increase could increase the load-carrying ability of the IL+graphene lubricants, thus reducing wear.

Table 2 shows mean friction coefficients and wear rate values at $25^{\circ} \mathrm{C}$. There is no direct relationship between the increase in viscosity with increasing graphene concentrations 
and friction coefficients. This could be explained by the wear decrease in the presence of graphene, which reduce contact between asperities and prevents friction increase.

Only $[\mathrm{EMIM}][\mathrm{DCA}]+0.5 \% \mathrm{G}$ is able to moderately reduce the friction coefficient with respect to [EMIM][DCA], which is not an efficient lubricant when compared with other imidazolium ILs with halogen-containing anions, such as [TFSI]. Figure S7 shows the friction-sliding distance records for all lubricants.

Both [EMIM] $[\mathrm{DCA}]+$ graphene dispersions are able to reduce the wear rate of steel with respect to the neat IL.

Table 2. Friction coefficients and wear rates.

\begin{tabular}{|l|c|c|}
\hline \multicolumn{1}{|c|}{ Lubricant } & $\begin{array}{c}\text { Friction } \\
\text { Coefficient }\end{array}$ & $\begin{array}{c}\text { Wear rate } \\
\left(\mathbf{m m}^{3} / \mathbf{N m}\right)\end{array}$ \\
\hline [EMIM][DCA] & $\begin{array}{c}0.19 \\
( \pm 0.003)\end{array}$ & $\begin{array}{c}2.76 \times 10^{-5} \\
\left( \pm 9.9 \times 10^{-7}\right)\end{array}$ \\
\hline [EMIM][TFSI] & $\begin{array}{c}0.09 \\
( \pm 0.01)\end{array}$ & $\begin{array}{c}1.66 \times 10^{-6} \\
\left( \pm 1.79 \times 10^{-7}\right)\end{array}$ \\
\hline [EMIM][DCA]+0.5\%G & $\begin{array}{c}0.17 \\
( \pm 0.02)\end{array}$ & $\begin{array}{c}1.26 \times 10^{-5} \\
\left( \pm 5.2 \times 10^{-7}\right)\end{array}$ \\
\hline [EMIM][TFSI]+0.5\%G & $\begin{array}{c}0.08 \\
( \pm 0.005)\end{array}$ & - \\
\hline [EMIM][DCA]+1\%G & $\begin{array}{c}0.17 \\
( \pm 0.012)\end{array}$ & $\begin{array}{c}1.24 \times 10^{-5} \\
\left( \pm 5.2 \times 10^{-7}\right)\end{array}$ \\
\hline [EMIM][TFSI]+1\%G & $\begin{array}{c}0.09 \\
( \pm 0.004)\end{array}$ & - \\
\hline
\end{tabular}

Fig.s 7a-7f shows micrographs of the wear tracks on the surface of AISI316L stainless steel after sliding against sapphire pins in the presence of the different lubricants. In contrast with the severe damage produced by [EMIM][DCA]-based lubricants (Fig.s 7a, $7 \mathrm{c}$ and $7 \mathrm{e}$ ), no wear track can be observed on the steel surface after lubrication with [EMIM][TFSI]+graphene nanofluids (Figs. $7 \mathrm{~d}$ and $7 \mathrm{f}$ ). The high viscosity of 
[EMIM][TFSI]+graphene could prevent the direct contact between surface asperities by operating under full fluid lubrication.

The severe wear produced on the steel surface in the presence of neat [EMIM][DCA] lubricant can be further appreciated in the 3D surface topography (Fig. 8a) and in the cross section profiles of the wear track (Fig. 8b), which show wide and deep wear tracks with material accumulation on the track edges. The depth and width of the wear track is clearly reduced by the addition of graphene.

a)

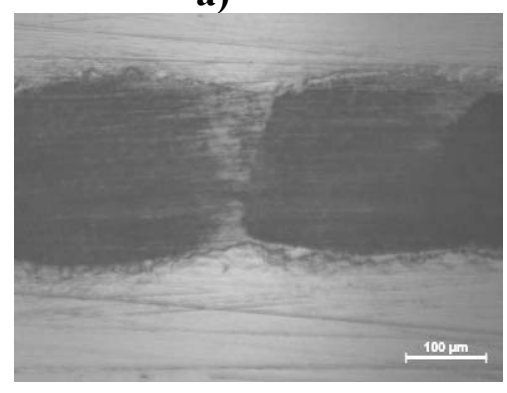

c)

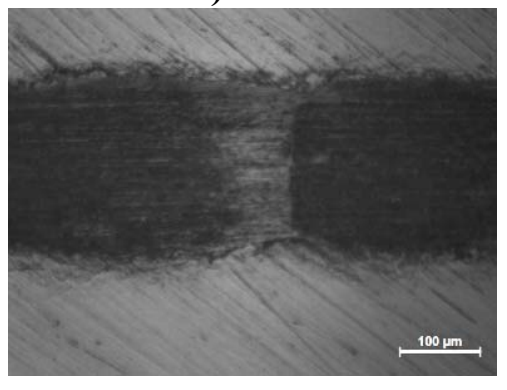

e)

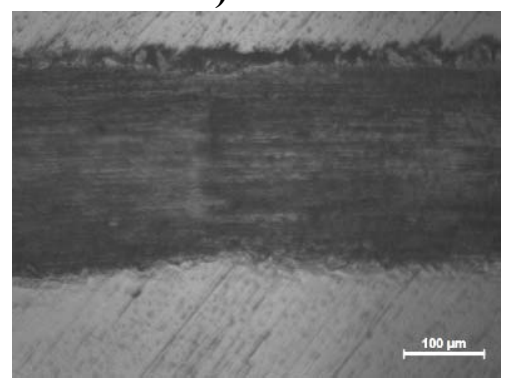

b)

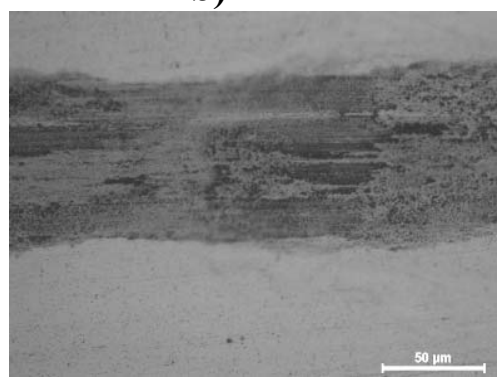

d)

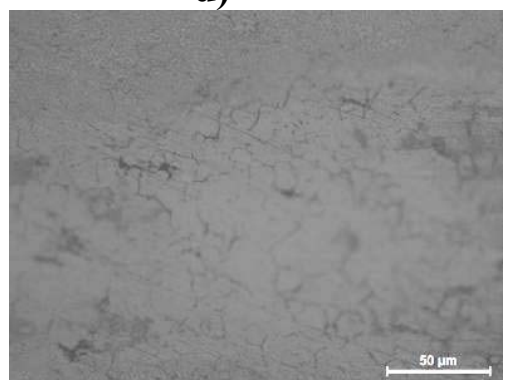

f)

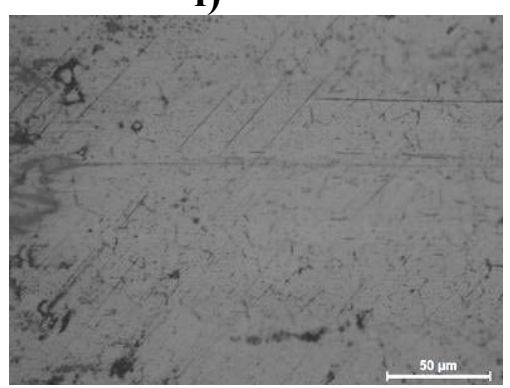

Fig. 7. Optical micrographs of wear tracks on steel disks after lubrication with:

a) [EMIM][DCA]; b) [EMIM][TFSI]; c) [EMIM][DCA]+0.5\%G; d) [EMIM][TFSI]+0.5\%G; e) [EMIM][DCA]+1\%G; f) [EMIM][TFSI]+1\%G. 
Figure S8 shows the surface topography and cross section for [EMIM][TFSI]. No measurable wear was found for $[\mathrm{EMIM}][\mathrm{TFSI}]+0.5 \% \mathrm{G}$ and $[\mathrm{EMIM}][\mathrm{TFSI}]+1 \% \mathrm{G}$.

a)

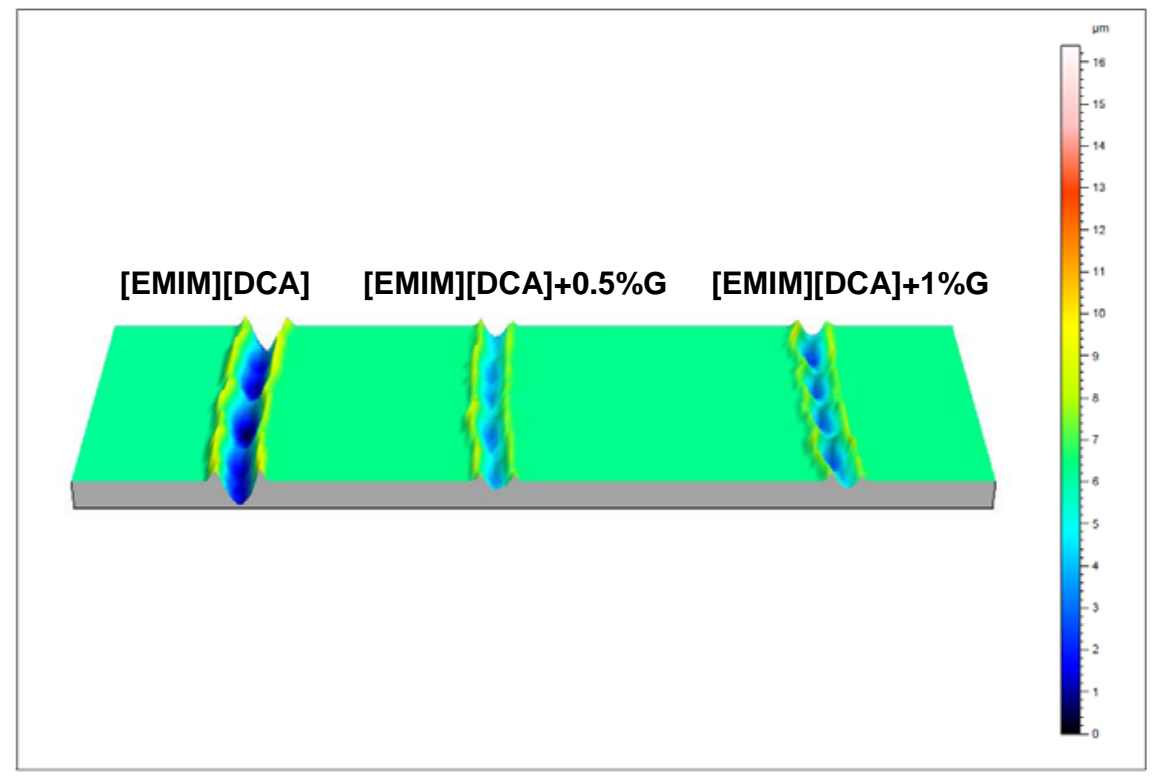

b)

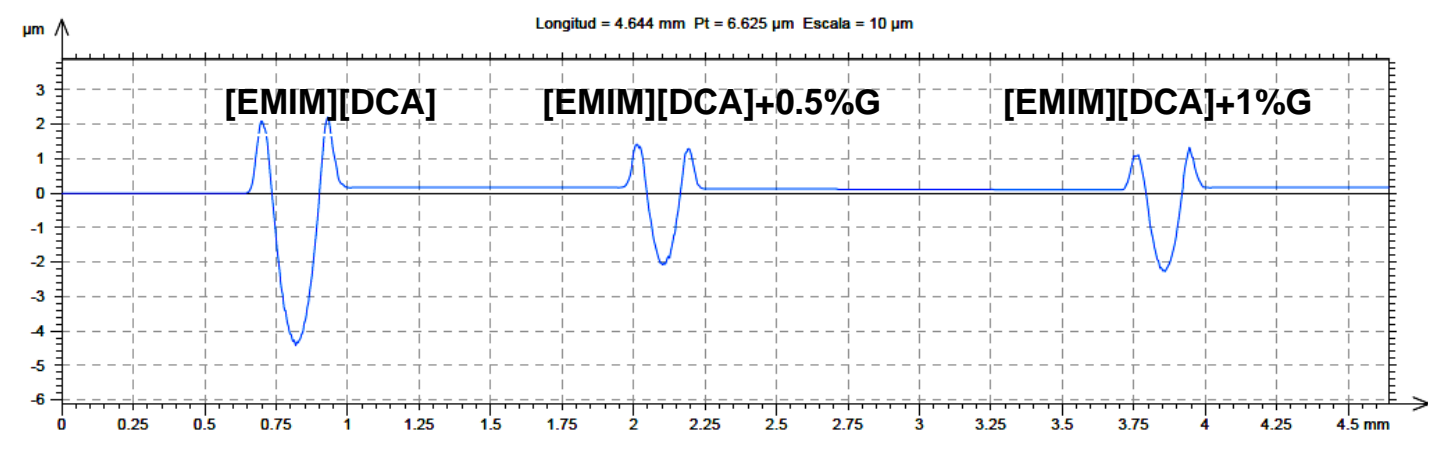

Fig. 8. Surface topography (a) and cross sections (b) of wear tracks on steel after lubrication with [EMIM][DCA] and [EMIM][DCA]+graphene dispersions.

In order to study the surface interactions between the nanofluids and the steel surface, Raman spectra were recorded (Fig. 9 for [EMIM][TFSI], and Fig. 10 for [EMIM][DCA]). 
Raman spectra of [EMIM][TFSI]+graphene dispersions (Fig. 9), show the characteristic $\mathrm{D}, \mathrm{G}$, and 2D bands (at 1360, 1598 and $2952 \mathrm{~cm}^{-1}$, respectively), with a $\mathrm{I}_{\mathrm{D}} / \mathrm{I}_{\mathrm{G}}$ intensity ratio of 0.8 , similar to that of as-received graphene [20,21].

The Raman spectrum inside the wear track on the steel surface after lubrication with neat [EMIM][TFSI] shows the presence of adsorbed IL (Fig. S9, Supporting Information).

Although the surface damage on steel after lubrication with [EMIM][TFSI]+graphene dispersions is negligible (Fig.s 7d and 7f), the Raman spectra of the sliding path shows bands assignable to the presence of graphene (Fig. 9).

a)

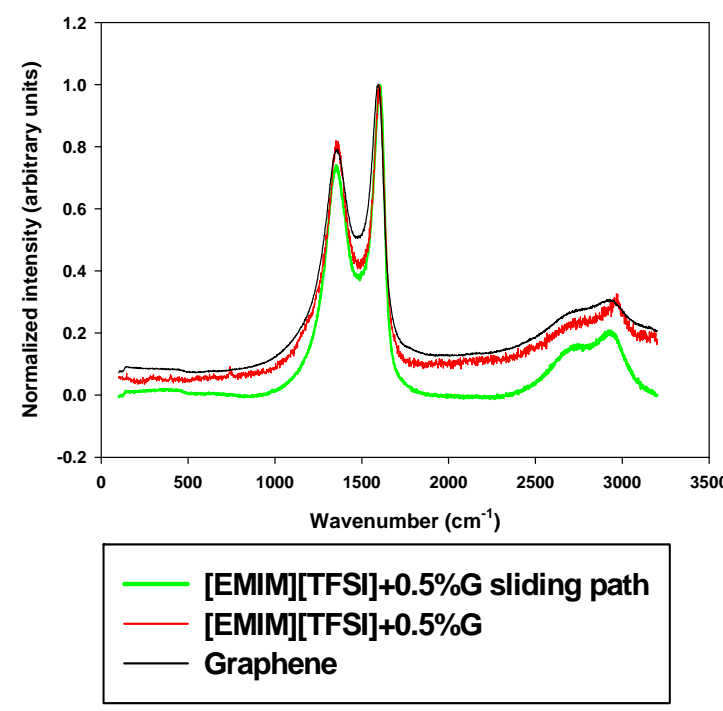

b)

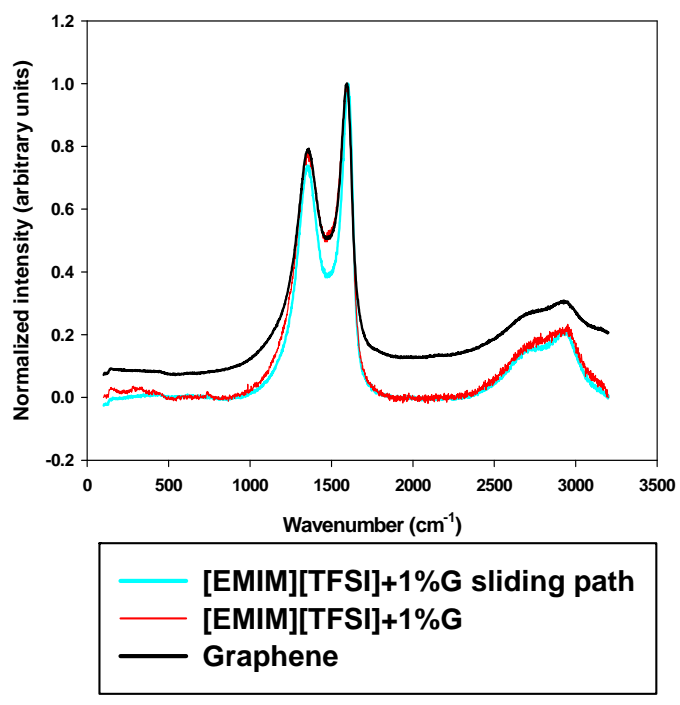

Fig. 9. Raman spectra of as-received graphene; [EMIM][TFSI]+graphene dispersion, and of the sliding path after lubrication with: a) [EMIM] [TFSI]+0.5\%graphene; b) [EMIM][TFSI]+1\%graphene. 
a)

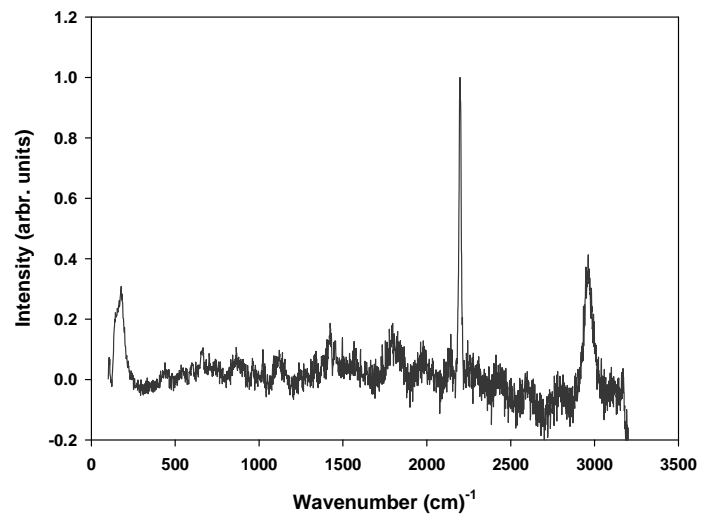

b)

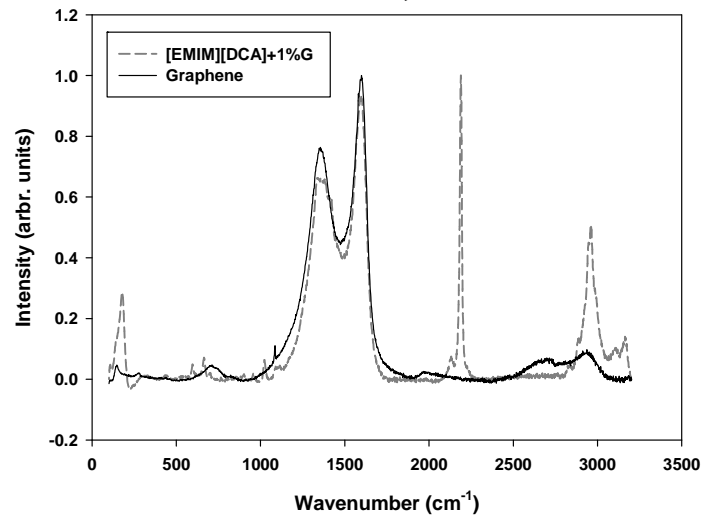

c)

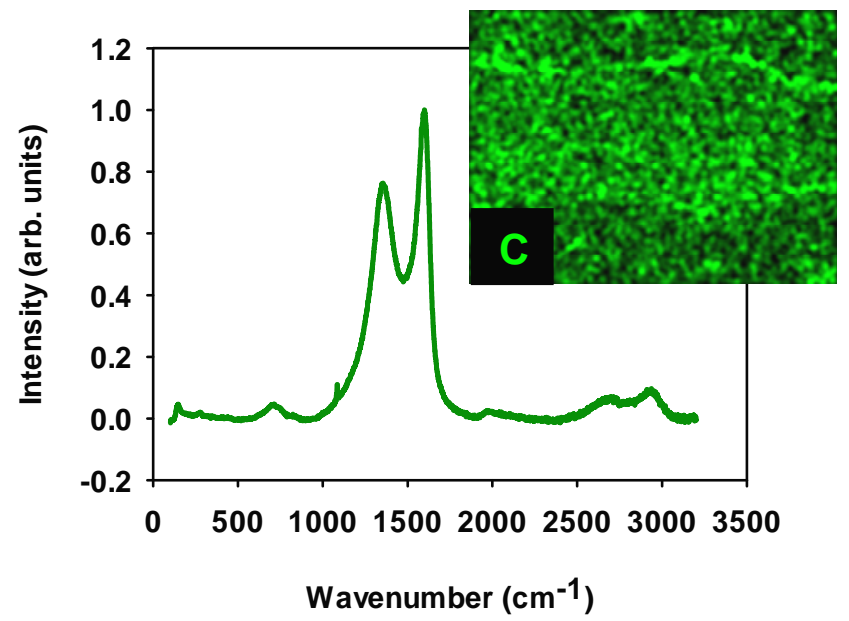

Fig. 10. Raman spectra: a) [EMIM][DCA]; b) Graphene (G) and the dispersion of 1 wt\% graphene in [EMIM][DCA]; c) Inside the wear track after lubrication with $[\mathrm{EMIM}][\mathrm{DCA}]+1 \% \mathrm{G}$ (EDX carbon element map shown in the inset).

It can be observed that the spectrum of the $[\mathrm{EMIM}][\mathrm{DCA}]+1 \% \mathrm{G}$ dispersion (Fig. 10b) is the addition of the spectra of graphene and [EMIM][DCA] (Fig. 10a).

In Fig. 10c, the Raman spectrum and the carbon element map, inside the wear track on the steel surface, are depicted. The Raman spectrum agrees with the results found for graphene in previous works $[20,21]$, which might be ascribed to the formation of a graphene layer on the steel surface during the tribological sliding test. 
Restuccia and Righi [71] proposed that the lubricating properties of graphene are due to its ability to passivate metal surfaces, while Klemenz et al. [72] proposed that it is due to the increase of the load carrying ability of the surfaces, that reduces penetration depths.

In a very recent work [73], Cooper et al. have shown that IL cations adsorb on stainless steel surfaces by strongly interacting with the chromium oxide layer. For bulky cations, the weaker cation-anion interactions at the adsorbed layer reduce lateral forces. In the case of ILs with the [EMIM] cation, as those used in the present study, the interactions with the stainless steel surface are always strong and so the effect of graphene addition is mainly that of wear reduction.

The severe wear found for [EMIM][DCA] as neat lubricant, gives rise to material loss in the form of wear debris particles as shown in the micrograph of Fig. 11a. EDX element map of the wear debris particles show that they are mainly composed of iron (Fig. 11b) from the stainless steel disk.

a)

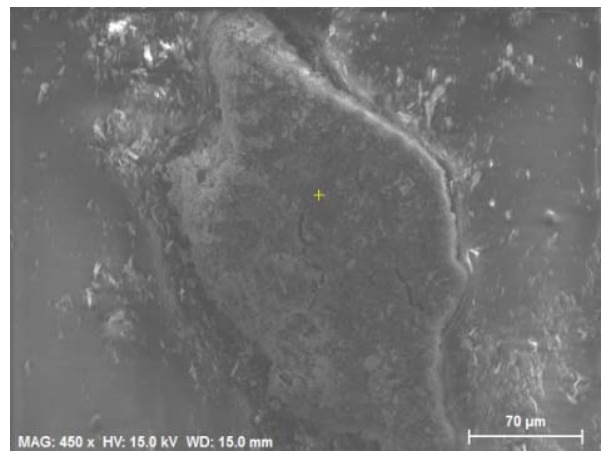

b)

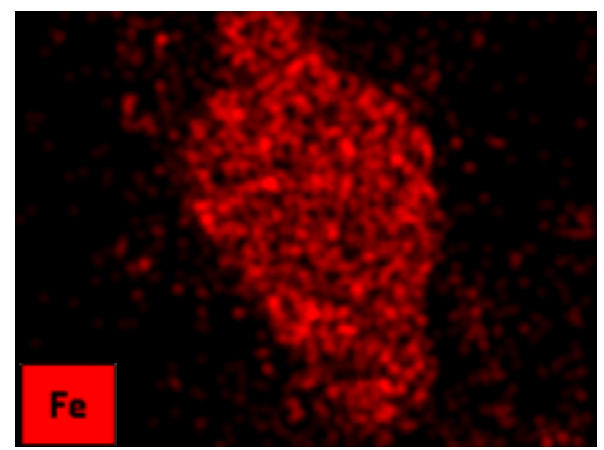

Fig. 11. a) SEM micrograph and b) EDX Fe element map of wear debris after lubrication with [EMIM][DCA].

The addition of $0.5 \mathrm{wt} . \%$ or $1 \mathrm{wt} \%$ graphene to [EMIM][DCA] reduces material loss with respect to neat IL (Table 2). In this case, only nanometric wear debris particles are 
found, and they remain adhered to graphene sheets, as can be observed in the TEM micrographs shown in Fig.s 12a and 12b, respectively. Thus, the anti-wear performance of graphene could be attributed to surface protection by a tribolayer and by preventing the formation of large abrasive wear debris particles.

a)

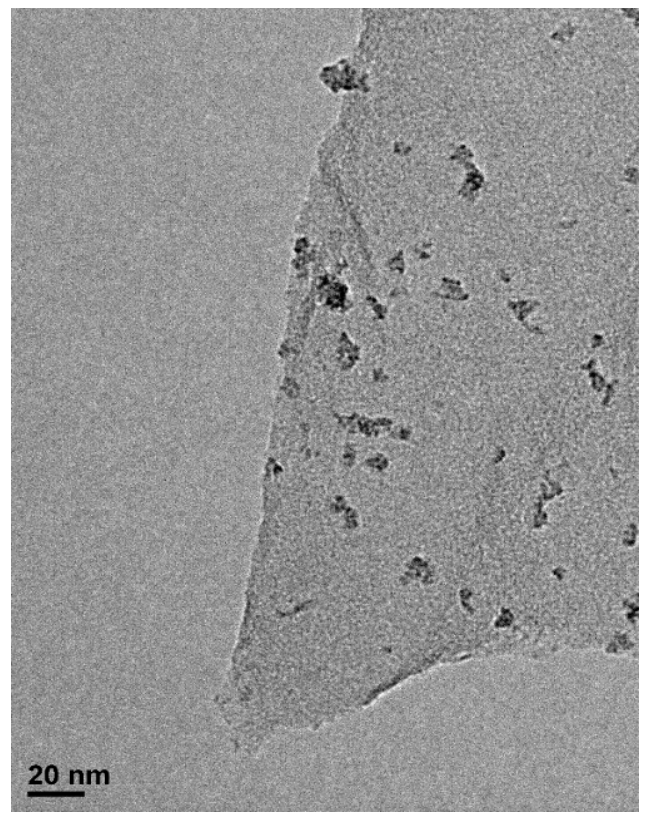

b)

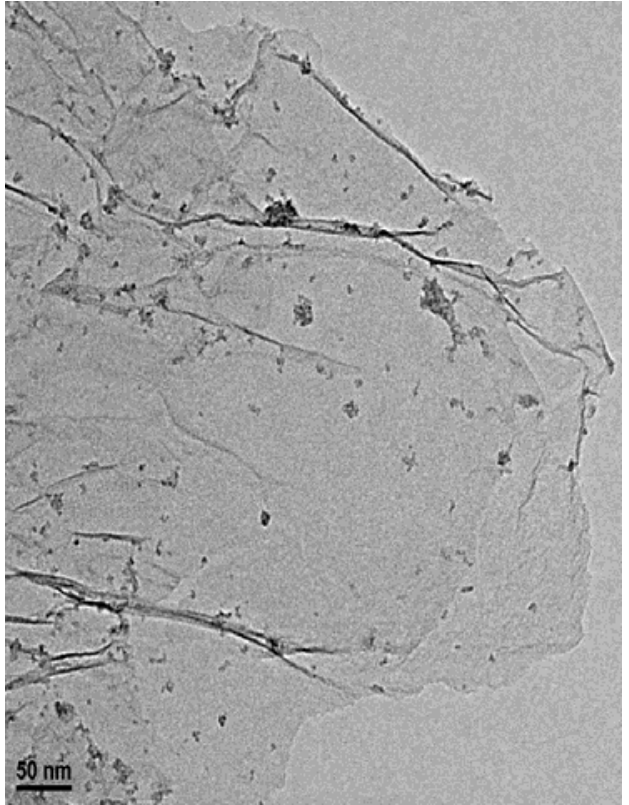

Fig. 12. TEM micrographs of wear debris after lubrication with: a) [EMIM][DCA]+0.5\%graphene; b) [EMIM][DCA]+1\%graphene.

\section{Conclusions}

The rheological behavior of neat 1-ethyl-3-methylimidazolium dicyanamide and bis(trifluoromethanesulfonyl)imide room temperature ionic liquids and of low few-layers graphene concentrations (0.05 and 0.1 wt.\%) in 1-ethyl-3-methylimidazolium bis(trifluoromethanesulfonyl)imide show a very good correlation with the Vogel-FulcherTammann-Hesse (VFTH) model. 
A critical concentration of $0.5 \mathrm{wt} \%$ graphene dispersed in the ionic liquids has been determined for constant viscosity values $(18.9 \mathrm{mPa} \cdot \mathrm{s}$ in [EMIM][DCA]) under increasing temperature values in the range between 357 and $400 \mathrm{~K}$. Nanofluids with higher graphene concentrations $(0.75 \mathrm{wt} . \%$ and $1 \mathrm{wt} . \%)$ show anomalous viscosity-temperature behaviors, with a linear viscosity increase with increasing temperature, from $306 \mathrm{~K}$ to $393 \mathrm{~K}$ for [EMIM][DCA]+1wt.\% graphene, and from 330K for [EMIM][TFSI]+0.75wt.\% graphene or [EMIM][TFSI]+1wt.\%graphene. This is attributed to the formation of stronger interactions between IL molecules and graphene sheets, which revert with temperature decrease.

The new graphene dispersions are able to reduce wear rates in sapphire-steel sliding contacts with respect to the neat ionic liquids, with similar or lower coefficients of friction. An outstanding tribological performance is found for [EMIM][TFSI]+graphene dispersions, which prevent surface damage. This better lubricating performance of the graphene-ionic liquid nanofluids is attributed to three causes: the higher load-carrying ability of the ionic liquid-graphene dispersions, the formation of a graphene surface layer deposited on the steel wear track, and the ability of graphene sheets to retain namometersize wear debris, thus avoiding the formation of large abrasive agglomerates of wear particles.

\section{Acknowledgments}

The authors acknowledge the Ministerio de Economía, Industria y Competitividad (MINECO, Spain), the EU FEDER Program (Grant \# MAT2017-85130-P), "Este trabajo es resultado de la actividad desarrollada en el marco del Programa de Ayudas a Grupos de Excelencia de la Región de Murcia, de la Fundación Séneca, Agencia de Ciencia y Tecnología de la Región de Murcia (Grant \# 19877/GERM/15)”. M.D. Avilés is grateful to MINECO for a research grant (BES-2015-074836). 


\section{References}

[1] Zhou F, Liang YM, Liu WM. Ionic liquid lubricants: designed chemistry for engineering applications. Chem Soc Rev 2009;38:2590-2599.

[2] Minami I. Ionic liquids in tribology. Molecules 2009;14:2286-2305.

[3] Bermúdez MD, Jiménez AE, Sanes J. Carrión, F.J. Ionic liquids as advanced lubricant fluids. Molecules 2009; 14:2888-2908.

[4] Torimoto T, Tsuda T, Okazaki K, Kuwabata S. New frontiers in materials science opened by ionic liquids. Adv Mater 2010;22:1196-1221.

[5] Saurín N, Espinosa T, Sanes J, Carrión FJ, Bermúdez MD. Ionic nanofluids in tribology. Lubricants 2015;3:650-663.

[6] Avilés MD, Saurín N, Sanes J, Carrión FJ. Bermúdez, M.D. Ionanocarbon lubricants. The combination of ionic liquids and carbon nanophases in tribology. Lubricants 2017;5:14.

[7] Somers AE, Howlett PC, MacFarlane DR, Forsyth M. A review of ionic liquid lubricants. Lubricants 2013;1:3-21.

[8] Zhou Y, Qu. J. Ionic liquids as lubricant additives. A review. ACS Appl. Mater. Interfaces 2017;9:3209-3222.

[9] Walden P. Ueber die Molekulargrösse und elektrische Leitfähigkeit einiger geschmolzenen Salze. (Molecular weights and electrical conductivity of several fused salts). Bull. Acad. Imper. Sci. St. Petersburg 1914;8:405-422.

[10] Wilkes JS. Zaworotko MJ. Air and water stable 1-ethyl-3-methylimidazolium based ionic liquids. Chem Commun 1992; 965-967. 
[11] Ye CF, Liu WM, Chen YX, Yu, LG. Room-temperature ionic liquids: a novel versatile lubricant. Chem Commun 2001; 2244-2245.

[12] Novoselov KS, Geim AK, Morozov SV, Jiang D, Zhang Y, Dubonos SV, Grigorieva IV, Firsov AA. Electric field effect in atomically thin carbon films. Science 2004;306:666-669.

[13] Geim AK, Novoselov KS. The rise of graphene. Nature Materials 2007;6:183-190.

[14] Berman D, Erdemir A, Sumant AV. Graphene: A new emerging lubricant. Materials Today 2014;17:31-42.

[15] Khare V, Pham MQ, Kumari N, Yoon HS, Kim C.S. Park JI, Ahn SH Grapheneionic liquid based hybrid nanomaterials as novel lubricant for low friction and wear. Appl Mater Interfaces 2013; 5: 4063-4075.

[16] Penkov O, Kim HJ, Kim HJ, Kim DE. Tribology of graphene: a review. Int J Precis Eng Manuf 2014; 15: 577-585.

[17] Zhao Y, Hu Z. Graphene in ionic liquids: collective van der Waals interaction and hindrance of self-assembly pathway. J Phys Chem B 2013;1117:10540-10547.

[18] Lin J, Wang L, Chen G. Modification of graphene platelets and their tribological properties as a lubricant additive. Tribol Lett 2011;41:209-215.

[19] Pu J, Wan S, Zhao W, Mo Y, Zhang X, Wang L, Xue Q. Preparation and tribological study of functionalized graphene-IL nanocomposite ultrathin lubrication films on $\mathrm{Si}$ substrates. J Phys Chem C 2011;115:13275-13284.

[20] Saurín N, Sanes J, Bermúdez MD. New graphene/ionic liquid nanolubricants. Materials Today Proc 2016;3S:S227-S232. 
[21] Saurín N, Avilés MD, Espinosa T, Sanes J, Carrión FJ, Bermúdez MD, Iglesias P. Carbon nanophases in ordered nanofluid lubricants. Wear 2017;376:747-755.

[22] Fernández J, Paredes X, Gaciño FM, Comuñas MJP, Pensado AS. Pressure-viscosity behaviour and film thickness in elastohydrodynamic regime of lubrication of ionic liquids and other base oils. Lubr Sci 2014;26:449-462.

[23] Jiménez AE, Bermúdez MD, Carrión FJ, Martínez-Nicolás G. Room-temperature ionic liquids as lubricant additives in steel-aluminium contacts: Influence if sliding velocity, normal load and temperature. Wear 2006;261:347-359.

[24] Hagiwara R., Ito Y. Room temperature ionic liquids of alkylimidazolium cations and fluoroanions. J Fluorine Chem 2000;105:221-227.

[25] Espinosa T, Jiménez M, Sanes J, Jimémez AE, Iglesias M, Bermúdez MD. Ultra-low friction with a protic ionic liquid boundary film at the water-lubricated sapphire-stainless steel interface. Tribol Lett 2014;53:1-9.

[26] Saurín N, Minami I, Sanes J, Bermúdez MD. Study of the effect of tribo-materials and surface finish on the lubricating performance of new halogen-free room temperature ionic liquids. Appl Surf Sci 2016;366:464-474.

[27] MacFarlane DR, Forsyth S, Golding J, Deacon GB. Ionic liquids based on imidazolium ammonium and pyrrolidinium salts of the dicyanamide anion. Green Chem $2002 ; 4: 444-448$.

[28] Pamies R, Espejo C, Carrión FJ, Morina A, Neville A, Bermúdez MD. Rheological behavior of multiwalled carbon nanotube-imidazolium tosylate ionic liquid dispersions. J Rheol 2017;61:279-289. 
[29] Waters AL, Palmese GR, Ultralow percolation threshold of single-walled carbon nanotube-epoxy composites synthesized via an ionic liquid dispersant/initiator. Mater Res Express 2014;1:035013.

[30] Sánchez LG, Espel JR, Onink F, Meindersma GW, de Haan AB. Density, viscosity and surface tension of synthesis grade imidazolium, pyridinium and pyrrolidinium-based room temperature ionic liquids. J Chem Eng Data 2009;54:2803-2812.

[31] MacFarlane DR, Golding J, Forsyth S, Forsyth M, Deacon GB. Low viscosity ionic liquids based on organic salts of the dicyanamide anion. Chem Commun 2001; 14301431.

[32] Fletcher SI, Sillars FB, Hudson NE, Hall P.J. Physical properties of selected ionic liquids for use as electrolytes and other industrial applications. J Chem Eng Data 2010;55:778-782.

[33] Quijada-Maldonado E, van der Boogaart S, Lijbers JH, Meindersma GW, de Haan A.B. Experimental densities, dynamic viscosities and surface tensions of the ionic liquid series 1-ethyl-3-methylimidazolium acetate and dicyanamide and their binary and ternary mixtures with water and ethanol at $\mathrm{T}=298.15$ to $343.15 \mathrm{~K}$. J Chem Thermodynamics 2012;51:51-58.

[34] McCrary PD; Beasley PA; Alaniz SA; Griggs CS, Frazier RM, Rogers RD. Graphene and graphene oxide can lubricate ionic liquids based on specific surface interactions leading to improved low temperature hypergolic performance. Angew Chemie 2012;51:9784-9787. 
[35] Naficy S, Jalili R, Aboutalebi SH, Gorkin RA, Konstantinov K, Innis PC, Spinks GM, Poulin P, Wallace GG. Graphene oxide dispersions: tuning rheology to enable fabrication. Mater Horiz 2014;1:326-331.

[36] Rasheed AK, Khalid M, Rashmi W, Gupta, TCSM, Chan A. Graphene-based nanofluids and nanolubricants. Review of recent developments. Renew Sustain Energy Rev 2016;63:346-362.

[37] Lalitha $\mathrm{M}$, Lakshmipathi S. Interface energetics of [Emim] $\mathrm{X}^{-}$and $[\mathrm{Bmim}]^{+} \mathrm{X}^{-}$ $(\mathrm{X}=\mathrm{BF} 4, \mathrm{Cl}, \mathrm{PF} 6, \mathrm{TfO}, \mathrm{Tf} 2 \mathrm{~N})$ based ionic liquids on graphene, defective graphene, and graphyne surfaces. J Molecular Liquids 2017;236:124-134.

[38] Pensado AS, Malberg F, Costa Gomes MF, Padua AAH, Fernández J, Kirchner B. Interactions and structure of ionic liquids on graphene and carbon nanotubes surfaces. RSC Adv 2014;4:18017-18024.

[39] Tuken T, Demir F, Kicir N, Sigircik G, Erbil M. Inhibition effect of 1-ethyl-3methylimidazolium dicyanamide against steel corrosion. Corrosion Sci 2012;59:110-118. [40] Tiago G, Restolho J, Forte A, Colaço R, Branco LC, Saramago B. Novel ionic liquids for interfacial and tribological applications. Coll Surf A: Physicochem Eng Aspects 2015;472:1-8.

[41] Kawada S, Sato K, Watanabe S, Sasaki S. Lubricating property of cyano-based ionic liquids against hard materials. J Mech Sci Technol 2017;31:5745-5750.

[42] Ghatee MH, Zare M, Zolghadr AR, Moosavi F. Temperature dependence of viscosity and relation with the surface tension of ILs. Fluid Phase Equilibria 2010;291:188-194. 
[43] Yoshida Y, Baba O, Saito G., Ionic liquids based on dicyanamide anion: influence of structural variations in cationic structures on ionic conductivity. J Phys Chem B 2007; 111:4742-4749.

[44] Reckeweg O, DiSalvo FJ, Schulz A, Blaschkowski B, Jagiella S, Schleid T. Synthesis, crystal structure and vibrational spectra of the anhydrous lithium dicyanamide Li[N(CN) $\left.)_{2}\right]$ Z Anor Allg Chem 2014;851-855.

[45] Seki S, Kobayashi T, Kobayashi Y, Takei K, Miyashiro H, Hayamizu K, Tsuzuki S, Mitsugi T, Umebayashi Y. Effects of cation and anion on physical properties of room temperature ionic liquids. J Molecular Liquids 2010;152:9-13.

[46] Arcifa A, Rossi A, Spencer ND. Adsorption and tribochemical factors affecting the lubrication of silicon-based materials by (fluorinated) ionic liquids. J Phys Chem C 2017;121:7259-7275.

[47] Fukushima T, Kosaka A, Ishimura Y, Yamamoto T, Takigawa T, Ishii N, Aida T. Molecular ordering of organic molten salts triggered by single-walled carbon nanotubes. Science 2003;300:2072-2074.

[48] Espejo C, Carrion FJ, Martínez D, Bermúdez MD. Multi-walled carbon nanotubeimidazolium tosylate ionic liquid lubricant. Tribol Lett 2013;50:127-136.

[49] Espinosa T, Sanes J, Bermudez MD. New alkylether tiazolium ionic liquid lubricants: surface interactions and tribological performance. ACS Appl Mater Interfaces 2016;8:18631-18639.

[50] Bulut S, Eiden P, Beichel W, Slattery JM, Beyersdorff TF, Schubert TJ, Krossing I. Temperature dependence of the viscosity and conductivity of mildly functionalized and non-functionalized [Tf2N] ionic liquids. ChemPhysChem 2011;12:2296-2310. 
[51] Seoane RG, Corderí S, Gómez E, Calvar N, González EJ, Macedo EA, Domínguez A. Temperature dependence and structural influence on the thermophysical properties of eleven commercial ionic liquids. Ind Eng Chem Res 2010;51:2492-2504.

[52] Beigi AAM, Abdouss M, Yousefi M, Pourmortazavi SM, Vahid A. Investigation on physical and electrochemical properties of three imidazolium-based ionic liquids (1hexyl-3-methylimidazolium tetrafluoroborate, 1-ethyl-3-methylimidazolium bis(trifluoromethylsulfonyl)imide and 1-butyl-3-methylimidazolium methylsulfate). J Molecular Liquids 2013;177:361-368.

[53] Shi M, Kou S, Yan X. Engineering the electrochemical capacitive properties of graphene sheets in ionic liquid electrolytes by correct selection of anions. ChemSusChem 2014;7:3053-3062.

[54] Weber H, Kirchner B. Complex structural and dynamical interplay of cyano-based ionic liquids. J Phys Chem B 2016;120:2471-2483.

[55] Zhang L, Chen L, Liu J, Fang X, Zhang Z. Effect of morphology of carbon nanomaterials on thermo-physical characteristics, optical properties and photo-thermal conversion performance of nanofluids. Renew Energy 2016;99:888-897.

[56] Liu J, Wang F, Zhang L, Fang X, Zhang Z. Thermodynamic properties and thermal stability of ionic liquid-based nanofluids containing graphene as advanced heat transfer fluids for medium-to-high temperature applications. Renew Energy 2014;63:519-523.

[57] Kheireddin BA, Lu W, Chen IC, Akbulut M. Inorganic nanoparticle-based ionic liquid lubricants. Wear 2013;303:185-190. 
[58] Shakourian-Fard M, Jamshidi Z, Bayat A, Kamath G. Meta-hybrid density functional theory study of adsorption of imidazolium- and ammonium-based ionic liquids on graphene sheet. J Phys Chem C 2015;119:7095-7108.

[59] Esfahani MR, Languri EM, Nunna MR. Effect of particle size and viscosity on thermal conductivity enhancement of graphene oxide nanofluid. Int Commun Heat Mass Transf 2016;76:308-315.

[60] Kalur GC, Frounfelker BD, Cipriano BH, Norman AI, Raghavan SR. Viscosity increase with temperature in cationic surfactant solutions due to the growth of wormlike micelles. Langmuir 2005;21:10998-11004.

[61] Chagnes A, Tougui A, Carré B, Ramoganathan N, Lemordant D. Abnormal temperature dependence of the viscosity of ethylammonium nitrate-methanol ionic mixtures. J Solution Chem 2004;33:247-255.

[62] Nanda R. Unusual linear dependency of viscosity with temperature in ionic liquid/water mixtures. Phys Chem Chem Phys 2016;18:25801-25805.

[63] Livovitz TA. Temperature dependence of the viscosity of associated liquids. J Chem Phys 1952;20:1088-1089.

[64] Vogel H. The temperature dependence law of the viscosity of fluids. Phys Zeitsch 1921;21:645-646.

[65] Fulcher GS. Analysis of recent measurements of the viscosity of glasses. J Amer Ceram Soc 1925; 8:339-355.

[66] Tammann G, Hesse W. The dependency of viscosity on temperature in hypothermic liquids. Zeitschrift Anorg Alleg Chem 1926;156:14. 
[67] Rodríguez H, Brennecke JF, Temperature and composition dependence of the density and viscosity of binary mixtures of water plus ionic liquid. J Chem Eng Data 2006;51:2145-2155.

[68] Carpio RA, King LA, Lindstrom RE, Nardi JC, Hussey CL. Density, electric conductivity and viscosity of several $\mathrm{N}$-alkylpyridinium halides and their mixtures with aluminium-chloride. J Electrochem Soc 1979;126:1644-1650.

[69] Voeltzel N, Giuliani A, Fillot N, Vergne P, Joly L. Nanolubrication by ionic liquids: molecular dynamics simulations reveal an anomalous effective rheology. Phys Chem Chem Phys 2015;17:23226-23235.

[70] Alcalde R, García G, Atilhan M. Aparicio S. Systematic study on the viscosity of ionic liquids. Measurements and prediction. Ind Eng Chem Res 2015; 54: 10918-10924.

[71] Restuccia P, Righi MC. Tribochemistry of graphene on iron and its possible role in lubrication of steel. Carbon 2016; 106: 118-124.

[72] Klemenz A, Pastewka L, Balakrishna S.G, Caron A, Bennewitz R. Moseler, M. Atomic scale mechanisms of friction reduction and wear protection by graphene. Nano Lett $2014 ; 14: 7145-7152$.

[73] Cooper PK, Wear CJ, Li H, Atkin R. Ionic liquid lubrication of stainless steel: friction is inversely correlated with interfacial liquid nanostructure. ACS Sustainable Chem Eng 2017; 5: 11737-11743. 


\title{
Antiwear performance of ionic liquid+graphene dispersions with anomalous viscosity-temperature behavior
}

\author{
R. Pamies, M.D. Avilés, J. Arias-Pardilla, T. Espinosa, F.J. Carrión, J. Sanes, M.D. Bermúdez \\ Grupo de Ciencia de Materiales e Ingeniería Metalúrgica. Departamento de Ingeniería de \\ Materiales y Fabricación. Universidad Politécnica de Cartagena. Campus de la Muralla del Mar. \\ C/Doctor Fleming, s/n. 30202-Cartagena (Spain)
}


Supporting Information.

1

2

3

4

5

6

7

8

9

10

11

12

13

14

15

16

17

18

19

20

21

22

23

24

25

26

27

28

29

30

31

32

33

34

35

36

37

38

39

40

41

42

43

44

45

46

47

48

49

50

51

52

53

54

55

56

57

58

59

60

61

62

63

64

65

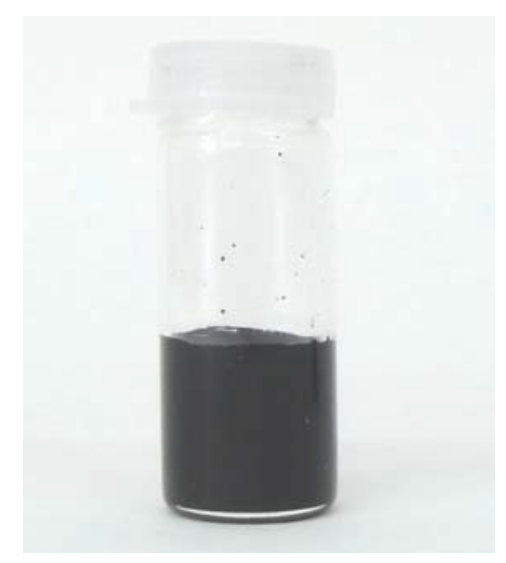

a) $[\mathrm{EMIM}][\mathrm{DCA}]+1 \% \mathrm{G}$

b) $[\mathrm{EMIM}][\mathrm{DCA}]+1 \% \mathrm{G}$ (after 30 days).

c) $[E M I M][D C A]+1 \% G$ (after 60 days).

Figure S1. a) [EMIM][DCA]+1 wt.\% graphene dispersion; b) After 30 days at room temperature;

c) After 60 days at room temperature. 
1

2

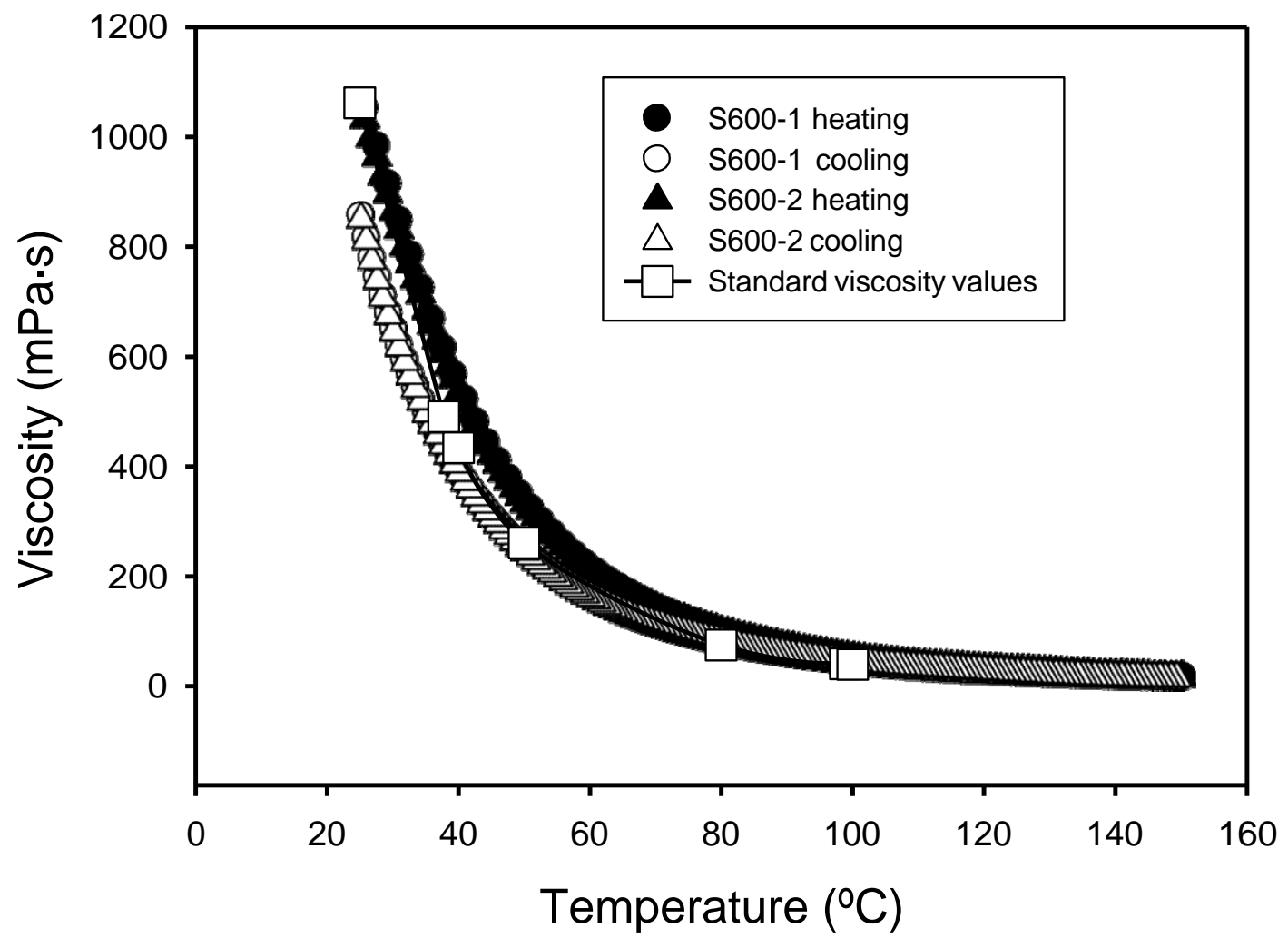

Figure S2. Experimental Calibration curves for $\mathrm{S} 600$ and viscosity standard values provided by the manufacturer (Canon Instrument Company, PA, USA). 


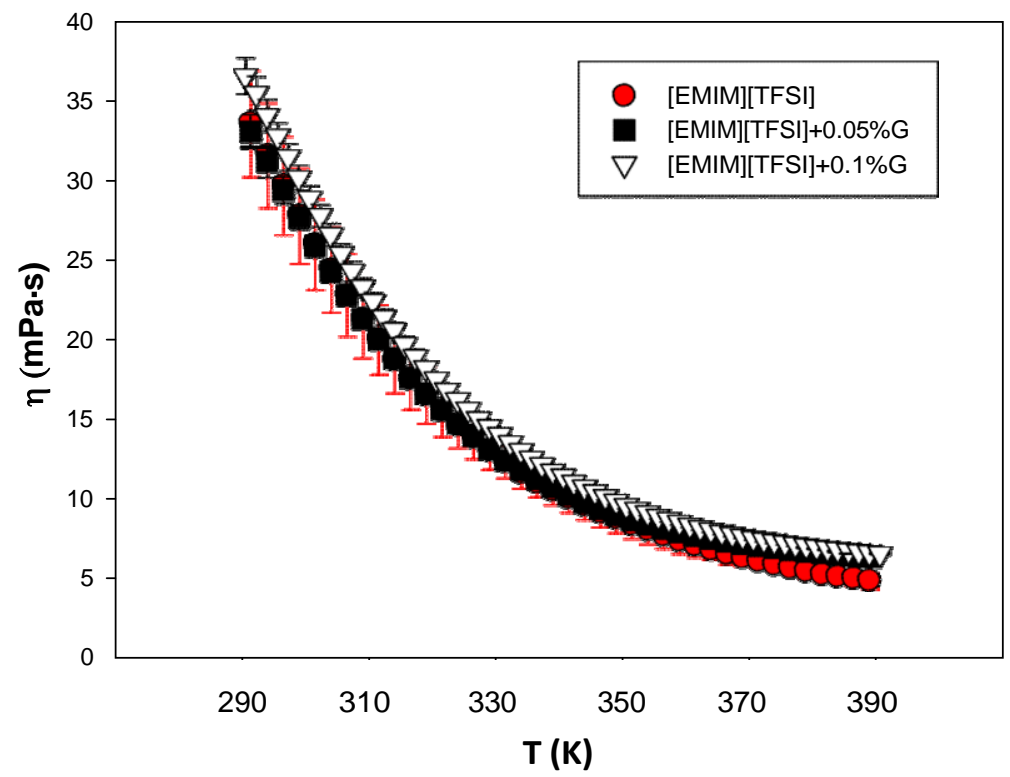

Figure S3. Viscosity-temperature curves for neat [EMIM][TFSI], and for diluted graphene dispersions [EMIM][TFSI]+0.05wt.\%G and [EMIM][TFSI]+1wt.\%G. 


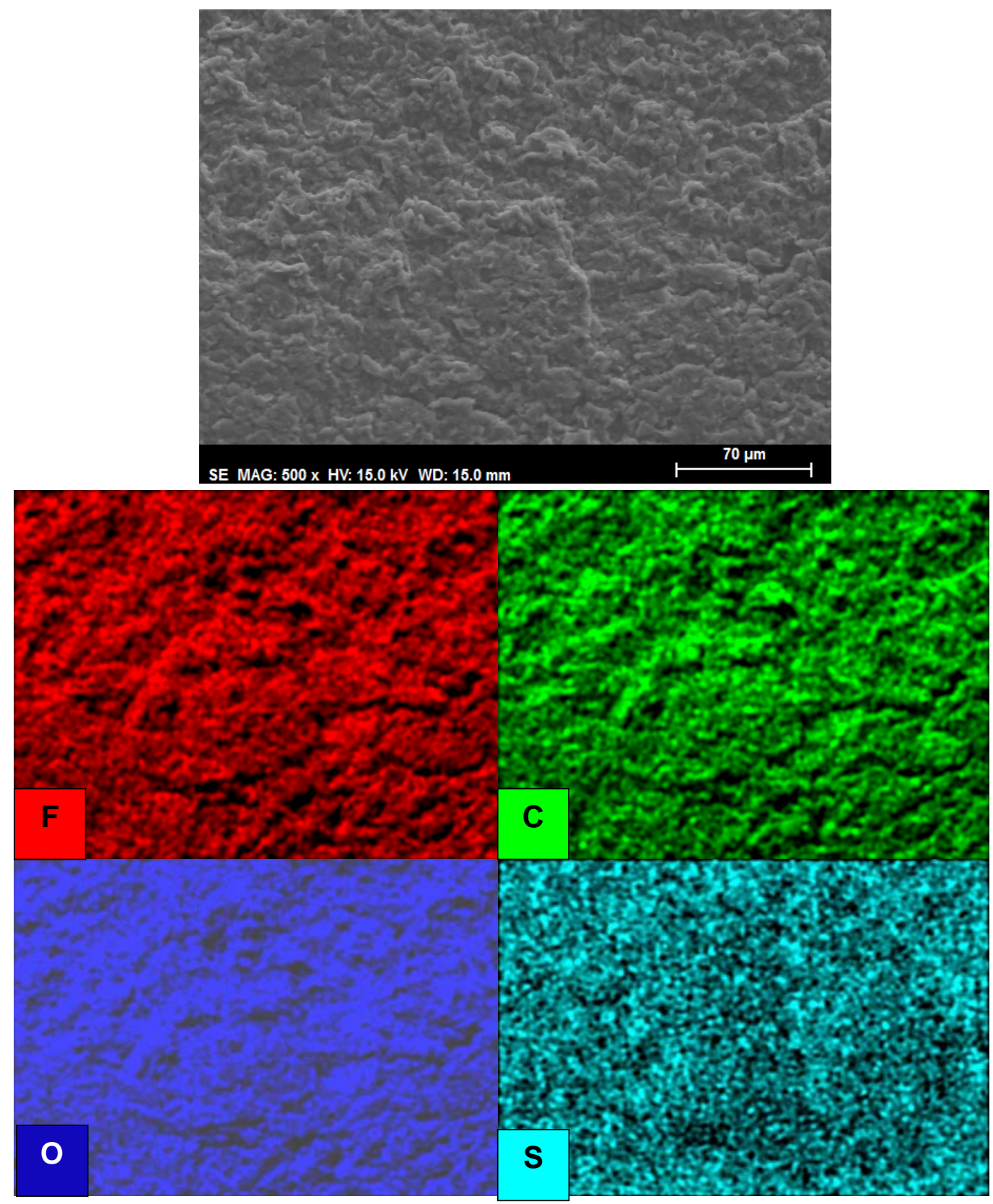

Figure S4. SEM micrograph and EDX element maps of dry graphene from [EMIM][TFSI]+0.75 wt.\% graphene after removal of excess [EMIM][TFSI] by centrifugation at $4400 \mathrm{rpm}$, washing with ethanol and drying in a vacuum oven at $80^{\circ} \mathrm{C}$ for 24 hours.. 


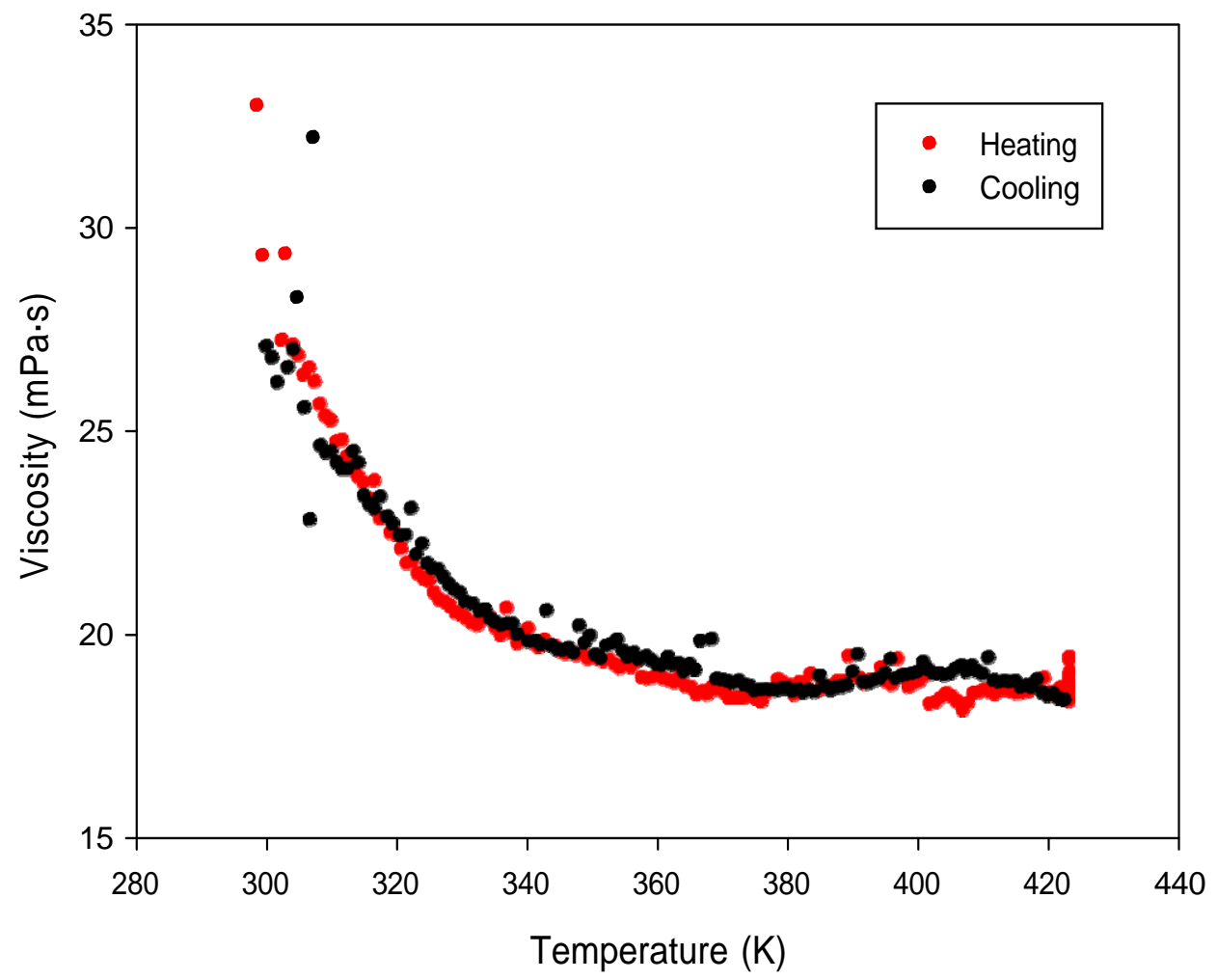

Figure S5. Heating-cooling viscosity cycle for [EMIM][DCA]+0.5 wt.\% graphene.

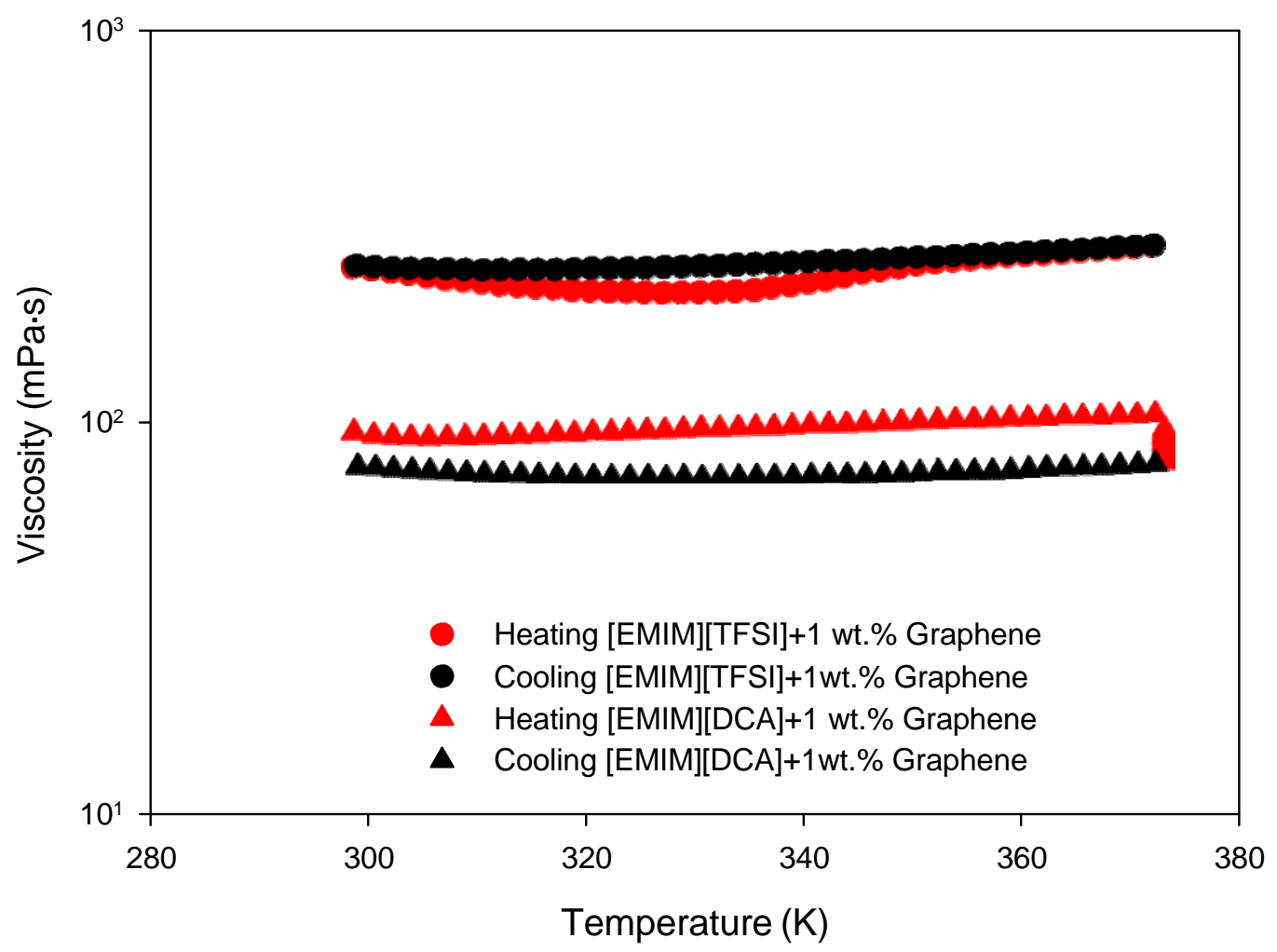

Figure S6. Heating-cooling viscosity cycles for IL+1wt.\% graphene dispersions. 


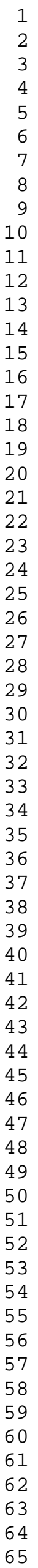

a)

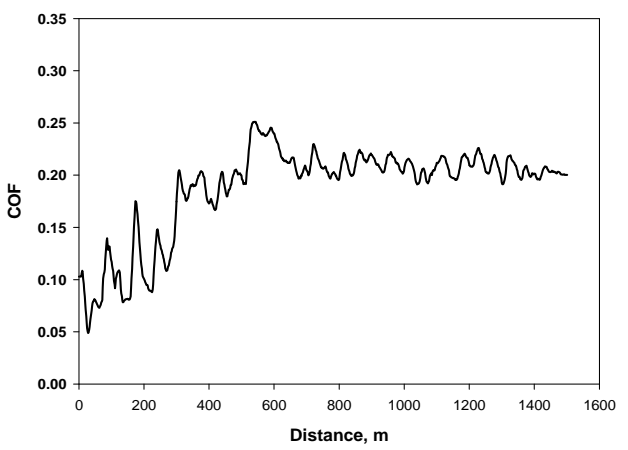

b)

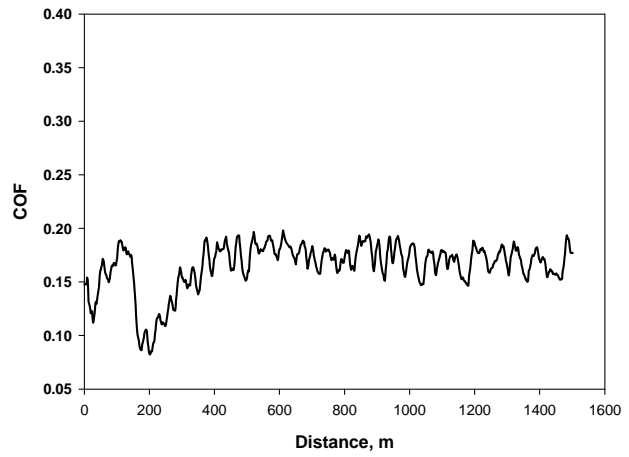

c)

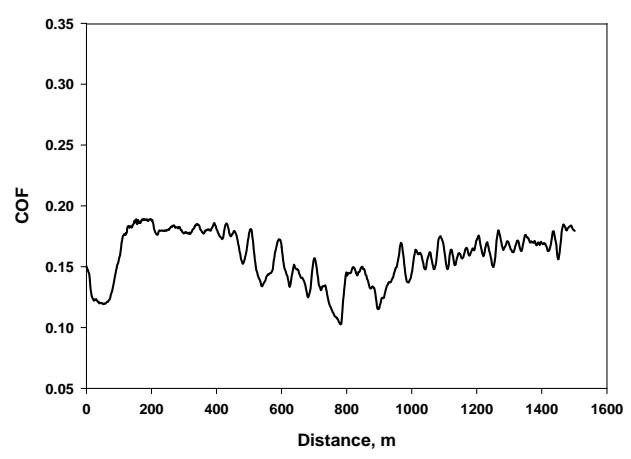

d)

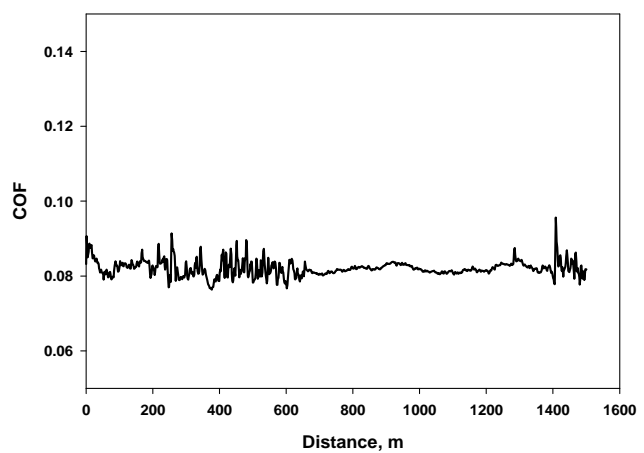

e)

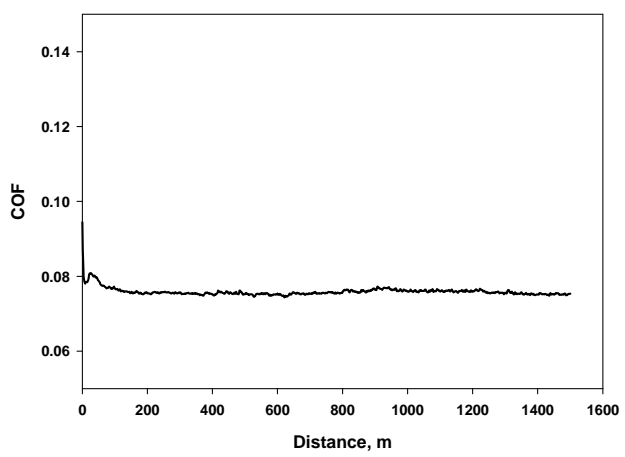

f)

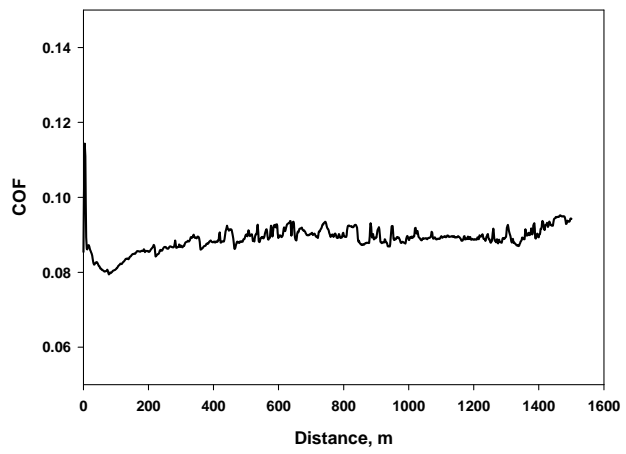

Figure S7. Friction vs sliding distance records for: a) [EMIM][DCA]; b) [EMIM][DCA]+0.5 wt.\% graphene; c) [EMIM][TFSI]+1 wt.\% graphene; d) [EMIM][TFSI]; e) [EMIM][TFSI]+0.5 wt.\% graphene; f) [EMIM][TFSI]+1 wt.\% graphene. 
a)
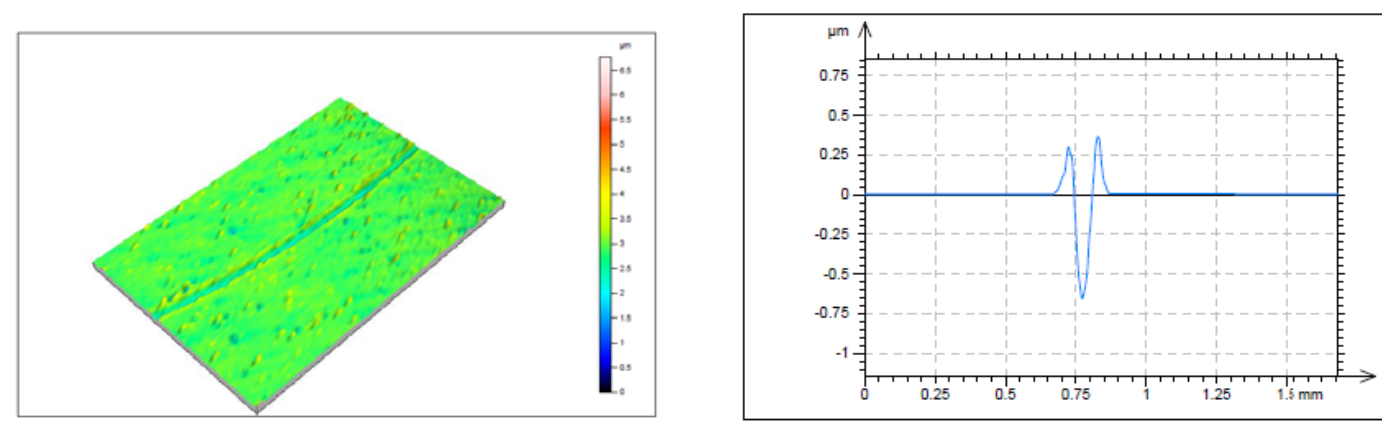

Figure S8 a) Surface topography and b) cross section profile of the wear track after lubrication with [EMIM][TFSI]. 
1

2

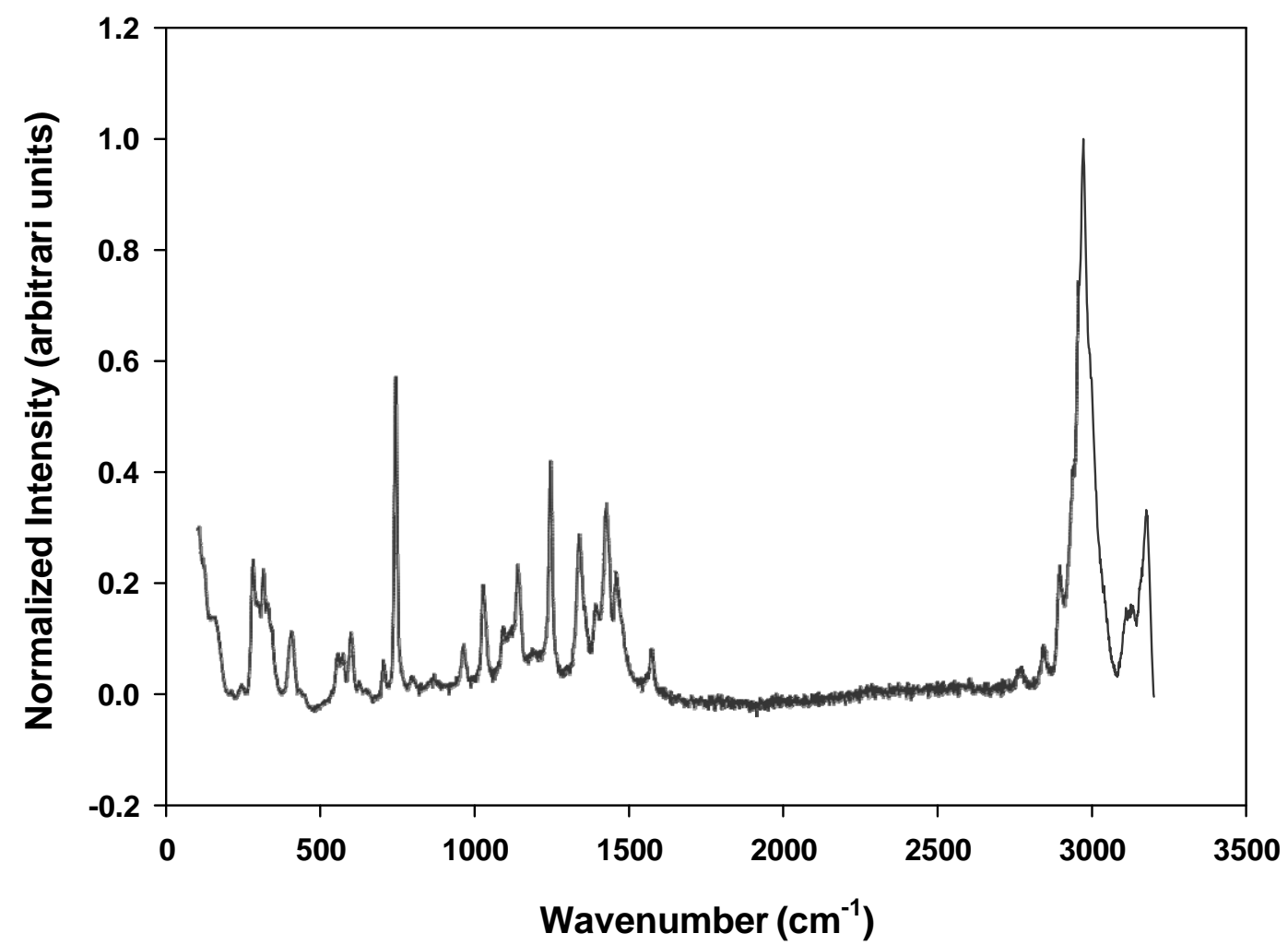

Figure S9. Raman spectrum of [EMIM][TFSI] inside the wear track on stainless steel. 